\title{
Uncertainty in gap filling and estimating the annual sum of carbon dioxide exchange for the desert Tugai forest, Ebinur Lake Basin, Northwest China
}

\author{
Dexiong Teng ${ }^{1,2}$, Xuemin He ${ }^{1,2}$, Jingzhe Wang ${ }^{1,2}$, Jinlong Wang ${ }^{1,2}$, Guanghui Lv ${ }^{\text {Corresp. } 1,2}$ \\ ${ }^{1}$ College of Resources and Environment Science, Xinjiang University, Urumqi, Xinjiang, China \\ 2 Key Laboratory of Oasis Ecology of Ministry of Education, Xinjiang University, Urumqi, Xinjiang, China \\ Corresponding Author: Guanghui Lv \\ Email address: Guanghui_xju@sina.com
}

In most eddy covariance studies, carbon flux measurements have a high defect rate for a variety of reasons. Obtaining the annual sum of carbon dioxide exchange requires imputation of data gaps with high precision and accuracy. This study used five methods to fill the gaps in carbon flux data and estimate the total annual carbon dioxide exchange of the Tugai forest in the arid desert ecosystem of Ebinur Lake Basin, Northwest China. The Monte Carlo method was used to estimate the random error and bias caused by gap filling. The results revealed that (1) there was a seasonal difference in the friction velocity threshold of nighttime flux, with values in the growing season and non-growing season of 0.12 and $0.10 \mathrm{~m} / \mathrm{s}$, respectively; (2) the five gap-filling methods explained $77 \%-84 \%$ of the data variability in the fluxes, and the random errors estimated by these methods were characterized by non-normality and leptokurtic heavy tail features, following the Laplacian (or double-exponential) distribution; (3) estimates of the annual sum of carbon dioxide exchange using the five methods at the study site in 2015 ranged from -178.25 to -155.21 $\mathrm{g} \mathrm{C} \mathrm{m}^{-2} \mathrm{yr}^{-1}$, indicating that the Tugai forest in the Ebinur Lake Basin is a net carbon sink. The standard deviation of the total annual carbon dioxide exchange sums estimated by the five different methods ranged from 3.15 to $19.08 \mathrm{~g} \mathrm{C} \mathrm{m}^{-2} \mathrm{yr}^{-1}$, with bias errors ranging from -13.69 to $14.05 \mathrm{~g} \mathrm{C} \mathrm{m}^{-2} \mathrm{yr}^{-1}$. This study provides a theoretical basis for the carbon dioxide exchange and carbon source/sink assessment of the Tugai forest in an arid desert ecosystem. In order to explore the functioning of the Tugai forest at this site, a greater understanding of the underlying ecological mechanisms is necessary. 
1 Uncertainty in gap filling and estimating the annual sum of carbon dioxide exchange for the 2 desert Tugai forest, Ebinur Lake Basin, Northwest China

3 Dexiong Teng ${ }^{1,2}$, Xuemin $\mathrm{He}^{1,2}$, Jingzhe Wang 1,2, Jinlong Wang ${ }^{1,2}$, Guanghui $\mathrm{Lv}^{1,2^{*}}$

$4{ }^{1}$ College of Resources and Environment Science, Xinjiang University, Urumqi, Xinjiang, China;

$5{ }^{2}$ Key Laboratory of Oasis Ecology of Ministry of Education, Xinjiang University, Urumqi,

6 Xinjiang, China

7 Corresponding Author: Guanghui Lv

8 Email address: ler@xju.edu.cn.

9 
10 Abstract: In most eddy covariance studies, carbon flux measurements have a high defect rate for

11 a variety of reasons. Obtaining the annual sum of carbon dioxide exchange requires imputation of data gaps with high precision and accuracy. This study used five methods to fill the gaps in carbon flux data and estimate the total annual carbon dioxide exchange of the Tugai forest in the arid desert ecosystem of Ebinur Lake Basin, Northwest China. The Monte Carlo method was used to estimate the random error and bias caused by gap filling. The results revealed that (1) there was a seasonal difference in the friction velocity threshold of nighttime flux, with values in the growing season and non-growing season of 0.12 and $0.10 \mathrm{~m} / \mathrm{s}$, respectively; (2) the five gap-filling methods explained $77 \%-84 \%$ of the data variability in the fluxes, and the random errors estimated by these methods were characterized by non-normality and leptokurtic heavy tail features, following the Laplacian (or double-exponential) distribution; (3) estimates of the annual sum of carbon dioxide exchange using the five methods at the study site in 2015 ranged from -178.25 to $-155.21 \mathrm{~g} \mathrm{C} \mathrm{m}^{-2}$ $\mathrm{yr}^{-1}$, indicating that the Tugai forest in the Ebinur Lake Basin is a net carbon sink. The standard deviation of the total annual carbon dioxide exchange sums estimated by the five different methods ranged from 3.15 to $19.08 \mathrm{~g} \mathrm{C} \mathrm{m}^{-2} \mathrm{yr}^{-1}$, with bias errors ranging from -13.69 to $14.05 \mathrm{~g} \mathrm{C} \mathrm{m}^{-2} \mathrm{yr}^{-1}$. This study provides a theoretical basis for the carbon dioxide exchange and carbon source/sink assessment of the Tugai forest in an arid desert ecosystem. In order to explore the functioning of the Tugai forest at this site, a greater understanding of the underlying ecological mechanisms is necessary.

\section{Introduction}

In recent decades, with the development of sonic anemometers, the eddy covariance method has become one of the direct techniques for determining the surface-atmosphere carbon dioxide exchange (Baldocchi, 2014). This method consists of calculating the covariance of fluctuations in vertical wind speed and gas concentration, providing valuable data on the dynamic interactions of the surface and atmosphere. At present, more than 800 eddy covariance stations around the world are monitoring the carbon dioxide and water exchange of the surface-atmosphere. These stations are located in forests, grasslands, farmlands, and other terrestrial ecosystems, concentrated in the grasslands of North America, Europe, and Africa, as well as in forest ecosystems (Baldocchi et al., 2018; Rebane et al., 2019). However, there have been few consecutive observations of material fluxes in arid desert ecosystems, leading to great difficulties in understanding the role of arid desert ecosystems in the global carbon cycle.

Eddy covariance (EC) is influenced by numerous factors during the measurement of carbon dioxide $\left(\mathrm{CO}_{2}\right)$ flux (e.g., limited turbulence, non-stationarity, blizzards, sand, precipitation, and instrument resolution), usually resulting in data loss or abnormalities. One study found that missing or abnormal data in carbon flux observations account for approximately $20 \%-60 \%$ of the total (Papale et al., 2006). This poses enormous difficulties for estimating the annual sum of carbon dioxide exchange. The important step in this estimation is gap filling. To solve this problem, a number of approaches have been proposed, including non-linear regression, look-up tables, mean diurnal variation methods (Falge et al., 2001), artificial neural networks (Braswell et al., 2005; Moffat et al., 2007; Papale and Valentini, 2003), marginal distribution sampling (Reichstein et al., 2005), data assimilation, and Bayesian model approaches (Gove and Hollinger, 2006). The 
51 differences among gap-filling methods for missing data and their impacts on the estimation of carbon dioxide exchange vary temporally and spatially in urban, forest, and grassland ecosystems (Kunwor et al., 2017; Liu et al., 2010; Moffat et al., 2007). Establishing a standard set of gapfilling methods can enhance comparability between different sites in regional and global flux networks (Falge et al., 2001). Models based on the light and temperature response are widely used for filling gaps in carbon flux observations of natural vegetation (Desai et al., 2005). Gap-filling approaches that rely on the average temperature underestimate flux values compared to those that preserve the observed variance as a consequence of Jensen's inequality, adding further bias to the long-term estimates of carbon dioxide exchange (Moffat et al., 2007). The introduction of additional predictors, such as vapor pressure deficit and soil moisture content, may reduce the bias that has been found to be proportional to the percentage of gaps filled in the annual sums of carbon dioxide exchange (Falge et al., 2001). Hagen et al. (2006) utilized two regression models to fill the gaps of carbon dioxide exchange in Howland Forest, Maine, USA, concluding that the greatest uncertainty comes from model differences. The Gaussian processes model and the radial basis function neural network have been shown to significantly improve model performance by capturing complex relationships in carbon dioxide exchange studies (Menzer et al., 2013; Menzer et al., 2015; Schmidt et al., 2007). There have been few studies on gap filling and the annual sum of carbon dioxide exchange in arid desert ecosystems, and uncertainty still remains in the estimation and evaluation of the annual sum of carbon dioxide exchange (Soloway et al., 2017). The evaluation of gap-filling uncertainty plays an important role in estimating regional carbon sink strength. The scientific comparison and evaluation of carbon flux gap-filling and the carbon budget

Arid desert ecosystems are playing an increasingly important role in the global carbon cycle (Donohue et al., 2013) and may even supplant tropical rainforests, affecting the interannual variation in the global carbon cycle (Poulter et al., 2014). Recent findings that desert regions remove carbon dioxide from the atmosphere at a magnitude of $\sim 100 \mathrm{~g} \mathrm{C} \mathrm{m}^{-2} \mathrm{yr}^{-1}$ suggest that these systems may explain at least a portion of the terrestrial carbon sink that has not been fully identified nor had its mechanisms explained in the global carbon cycle (Jasoni et al., 2005; Ma et al., 2014; Stone, 2008; Wohlfahrt et al., 2008; Xie et al., 2009). Irrigated saline/alkaline arid land is a potentially large carbon sink in the terrestrial ecosystem (Li et al., 2015). The study of carbon flux has direct implications for the missing global carbon sink. The Ebinur Lake Basin is a typical salinized area (Wang et al., 2019b). The Tugai forest is the only natural forest community in the Ebinur Lake Basin, and its contribution to the carbon dioxide exchange of the region cannot be overlooked. Estimating the annual sum of the carbon dioxide exchange of the Tugai forest can provide insight into the issue of the missing carbon sink to a certain extent.

In this study, EC techniques were used to obtain continuous records of the carbon flux of the Tugai forest on the northern bank of the Aqikesu River in the Ebinur Lake Wetland National Nature Reserve, Northwest China. We evaluated the ability of five gap-filling methods to analyze random uncertainties and bias in order to provide more robust estimations of the annual sums of the carbon dioxide exchange from the Tugai forest. In addition, the impacts of these different gapfilling methods - the artificial neural network for backward propagation algorithm (ANN), the 
92 radial basis function (RBF) neural network, the Gaussian processes model (GP), the regularized

hierarchical linear model (HLM) with a Bayesian framework, and marginal distribution sampling (MDS) - on the annual carbon dioxide exchange in the Tugai forest were examined and the random uncertainties were studied.

\section{Materials and Methods}

\subsection{Site description}

The study site is located in the Ebinur Lake Wetland National Nature Reserve in the Bortala Mongolian Autonomous Prefecture of the Xinjiang Uygur Autonomous Region, Northwest China $\left(44^{\circ} 37^{\prime} 05^{\prime \prime}-45^{\circ} 10^{\prime} 35^{\prime \prime} \mathrm{N}, 82^{\circ} 30^{\prime} 47^{\prime \prime}-83^{\circ} 50^{\prime} 21^{\prime \prime} \mathrm{E}\right)$. The Xinjiang Ebinur Lake Wetland National Natural Protection Zone Management Bureau approved site access. With a temperate continental climate, the reserve located in the Alataw Pass (Fig. 1a) is a typical arid desert, featuring high temperatures, drought, and sufficient sunshine in summer, and dry and cold conditions in winter. With strong winds from the Alataw Mountain Pass, the loose and relatively thick Quaternary sediment provides a rich sand source for sand shifting, and the soil salinization is generally pronounced. Typical soils in the study area are gray desert soil, gray-brown desert soil, and aeolian sandy soil. The azonal soil is dominated by saline soil, and supplemented by meadow soil, bog soil, and brown calcic soil (Jin et al., 2010; Wang et al., 2019a). The annual average temperature in the basin is $6-8^{\circ} \mathrm{C}$, the annual precipitation is approximately $100 \mathrm{~mm}$, and the annual average sunshine is $2,800 \mathrm{~h}$. The ecological environment is relatively fragile and consists primarily of two ecological ecosystems: the wetland ecosystem and the arid grassland-forest ecosystem (Fig. 1b). The flux observation tower stands near the Aqikesu River $\left(44^{\circ} 37^{\prime} 4.8^{\prime \prime} \mathrm{N}, 83^{\circ} 33^{\prime} 59.4^{\prime \prime} \mathrm{E}\right)$ in the forest-desert transitional zone influenced by lakes and rivers (Fig. 1e). The dominant species of plants in this region are Populus euphratica, Haloxylon ammodendron, and Phragmites australis, with a combined coverage of more than $60 \%$, accompanied by a variety of shrubs, herbs, and desert-specific short-lived plants (He et al., 2014; He et al., 2015; Wang et al., 2019). During the observation period, the annual average temperature at the flux tower was $9^{\circ} \mathrm{C}$, the highest temperature was $43^{\circ} \mathrm{C}$, and the lowest temperature was $-26^{\circ} \mathrm{C}$. More weather conditions are shown in Fig. 2.

Fig. 1. Aerial photograph of the tower site

(a) Location map of the Ebinur Lake Basin, (b) Location map of the measurement tower, (c) aerial photo of the tower site in August (Photograph credit: Jinlong Wang), (d) photograph of the tower site in May (Photograph credit: Dexiong Teng), and (e) remote sensing image in June and the average footprint for the entire observation period (Kormann and Meixner, 2001). The measurement tower is marked with a red circle. The white lines represent isopleths of the average contributions.

Fig. 2. Meteorological observations during the year of measurement

Half-hour averaged values of (a) air temperature $\left(T_{\text {air }}\right)$, (b) precipitation, (c) global radiation 
$(\mathrm{Rg}),(\mathrm{d})$ wind speed, and (e) relative humidity $(\mathrm{RH})$ during the observation period

\subsection{Carbon flux data observation and processing}

The data for this study were obtained from the Ebinur Lake Desert Ecosystem Flux Tower (2012XJ-AibiHu-OPEC) using an eddy covariance system consisting of a 3-D sonic anemometer (CSAT3, Campbell Scientific, USA) and an open-path infrared gas analyzer (EC150, Campbell Scientific, USA). The instruments were installed on the southwest side of the tower above the forest canopy at a height of $15.0 \mathrm{~m}$ ( $\sim 4.0 \mathrm{~m}$ above the mean canopy height). Total $\mathrm{CO}_{2}$ fluxes were measured from January 1, 2015 to December 31, 2015. Using EddyPro 6.2.1 software, 30-min averaged values were calculated, resulting in 17,520 observations (Table 1). Webb, Pearman, and Leuning (WPL) correction was used during the data pre-processing (Webb et al., 2010). Due to extremely low temperatures and instrument failure, 4,858 (approximately 27.73\%) of the data observations were missing. Based on the stationarity test (Foken and Wichura, 1996; Mauder et al., 2013), the observations were divided into 3 quality classes $(0,1$, and 2$)$. Only high-quality data were selected to establish the model, and 5,784 (approximately 33.01\%) of the data observations with a rank other than 0 were excluded. Based on changes in surface vegetation, the year can be divided into the growing season (May-September) (Munir et al., 2015) and the non-growing season (January-April and October-December). This study divided the data into daytime and nighttime periods based on the sunrise and sunset times at the location of the flux tower. The observation time of the daytime data extended from sunrise to sunset, and the observation time of the nighttime data extended from sunset to sunrise. There were 8,924 daytime observations, accounting for $50.94 \%$ of the total and 8,596 nighttime observations, accounting for $49.06 \%$. The total count of null and low-quality observations was 6,735 , accounting for $38.44 \%$. Thus, there was a large amount of missing data, and data gap-filling faced enormous challenges.

Corresponding to the 30-min carbon dioxide flux $\left(\mathrm{F}_{\mathrm{C}}\right)$ observation data, eight explanatory variables, including soil temperature, air temperature, relative humidity, incident radiation, scattered radiation, saturated vapor pressure deficit, normalized difference vegetation index (NDVI), and water vapor partial pressure, were selected as the driving factors for the gap-filling models. Partial explanatory variables needed to be converted (Table 1). The selected meteorological variables were normalized by mapping all explanatory variables to $(0,1)$ via linear transformation and using the 2 variables of growing and non-growing to describe the season, both of which are binary ( 0 or 1 ). Based on the sunrise and sunset times, the data were classified into 2 types, daytime and nighttime, which were represented by binary variables. The observation data were divided into 3 parts: high-quality data used for training and testing models; data used to calculate the annual exchange of carbon flux; and gaps.

Table 1. Data source of the driving factors and their corresponding pre-processing

\subsection{Net ecosystem carbon dioxide exchange}

The net ecosystem carbon dioxide exchange (NEE) between the ecosystem and the atmosphere can be estimated as the sum of the vertical eddy covariance and the storage term: 


$$
\mathrm{NEE}=\mathrm{F}_{\mathrm{C}}+\mathrm{F}_{\mathrm{S}}
$$

The low density of the Tugai forest canopies, which is favorable to eddy penetration, can reduce the importance and frequency of storage events. The lower the vegetation height, the less storage of $\mathrm{CO}_{2}$. In addition, the effect of the storage terms on the carbon uptake characteristics over long-term time scales is not significant since the cumulative value of the storage terms in the long-term is approximately equal to 0 (Massman and Lee, 2002). In this study, the storage terms were considered to be negligible compared with the terms associated with eddy covariance fluctuation.

\subsection{Night friction velocity threshold}

The friction velocity $u^{*}$ is intended to capture the turbulence characteristics in the vicinity of the surface. In a general way, $u^{*}$ can be expressed as a fraction of the average wind speed $u$ :

$$
u^{*} \approx \frac{u}{\Pi}
$$

where the parameter $\Pi$ is the roughness index. We used standardized major axis (SMA) regression to compare the roughness difference between the growing season and the non-growing season (Warton et al., 2012).

Due to the relatively stable atmospheric stratification at night, the carbon flux observed using eddy covariance techniques cannot truly represent the surface-atmosphere carbon dioxide exchange. Nighttime data processing was an important step in the flux data processing. The uncertainty of the annual sum of ecosystem carbon exchange caused by different treatment methods can reach $150 \mathrm{~g} \mathrm{C} \mathrm{m}^{-2} \mathrm{yr}^{-1}$ (Williams et al., 2009). The bias due to the data processing methods in this study area, as well as the estimated bias from the gap-filling techniques, may be greater. To correct selective systematic errors, the international flux community usually excludes nighttime observations below the friction velocity threshold in order to ensure that eddy covariance techniques are measured under strong turbulence conditions (Aubinet and Feigenwinter, 2010). Currently, despite theoretical and practical deficiencies, the empirical and effective method for processing nighttime negative flux is filtered by the friction velocity threshold (Aubinet and Feigenwinter, 2010). The friction velocity threshold can be determined by testing the relationship between the flux and the friction velocity, since, in theory, carbon dioxide flux and friction velocity are independent. When the friction velocity is lower than this threshold, $\mathrm{F}_{\mathrm{C}}$ decreases as the friction velocity decreases. The nighttime flux data of the growing and non-growing seasons were sorted based on the increment of $u^{*}$, and the friction velocity thresholds for the growing and non-growing seasons were then determined. A total of 45 levels were set, and the thresholds were derived by statistically comparing (using the two-sample Wilcoxon test) the flux average at each $u^{*}$ level with the flux average at the next higher $u^{*}$ level.

\subsection{Detection of abnormal data points}

The technique of using eddy covariance to observe carbon flux is susceptible to environmental factors such as rapid changes in turbulence, as well as the instrumentation itself. 
204 The 30-min data obtained from processing the observed raw data contained a large number of gaps 205 and abnormal values, which deviated from the range of normal data variation (Li et al., 2005). 206 Given the relatively clear daily variation of the carbon flux data, this study divided the carbon flux 207 data into 48 parts according to the time of day and defined any carbon flux data beyond the upper 208 and lower limits as abnormal points. For outliers in the continuous data, this study used 7 days as 209 the window to determine the difference between the median of 3 consecutive data points $\left(\mathrm{D}_{i}\right)$. The

$$
\mathrm{D}_{\mathrm{i}}=\left(\mathrm{F}_{\mathrm{C} i}-\mathrm{F}_{\mathrm{C} i-1}\right)-\left(\mathrm{F}_{\mathrm{C} i+1}-\mathrm{F}_{\mathrm{C} i}\right) \text {, }
$$

where $\mathrm{F}_{\mathrm{C}}$ is the carbon dioxide flux, and $i$ is the ordinal number of the observation data for $30 \mathrm{~min}$. When $\mathrm{D}_{i}$ satisfies the relationship

$$
\mathrm{Md}+(\mathrm{z} * \mathrm{MAD} / 0.6745)>\mathrm{D}_{i}>\mathrm{Md}-(\mathrm{z} * \mathrm{MAD} / 0.6745),
$$

the corresponding $i^{\text {th }}$ observation data point is normal; otherwise, it is defined as an "abnormal point" and is eliminated. (Daytime and nighttime data were processed separately.) $\mathrm{Md}$ is the median of the $\mathrm{F}_{\mathrm{C}}$ differences between all sets of two adjacent points. MAD $=$ median $\left(\left|\mathrm{D}_{i}-\mathrm{Md}\right|\right)$ and is the median of all $\left|\mathrm{D}_{i}-\mathrm{Md}\right|$ for a 7-day window. In this study, the sensitivity coefficient $z$ of the artificially defined outlier identification was set to 5.5 .

\subsection{Gap-filling methods}

Given the actual conditions of a site, selecting the appropriate flux data processing method and reducing the uncertainty of the flux data estimation are important issues that need to be understood and analyzed by the flux community. The effectiveness of different methods for filling gaps in carbon dioxide flux $\left(\mathrm{F}_{\mathrm{C}}\right)$ data has been investigated. This study used ANN, RBF, GP, HLM, and MDS to fill the gaps. The high-quality data were randomly divided into 2 parts, $80 \%$ of which were used to train the model and $20 \%$ to test the model. In order to avoid overfitting, 4 different methods (ANN, GP, HLM, and RBF) were used for model training before the best model for each method was selected and used for prediction. In the data analysis, the neuralnet, RSNNS, laGP, and INLA packages ( $\mathrm{R}$ language) were used to train and test ANN, RBF, GP, and HLM, respectively. The gap-filling model was evaluated in terms of 3 statistical factors: the coefficient of determination $\left(\mathrm{R}^{2}\right)$, root mean square error (RMSE), and bias error (BE).

\subsubsection{ANN and RBF}

For artificial neural network training, the input data were passed through the nodes using weighted connections, the error between the predicted and actual output values was calculated by backpropagation, and the weight was adjusted to minimize the error (Braswell et al., 2005; Papale and Valentini, 2003). The training data were pre-sampled to ensure equal coverage under different conditions, and fuzzy values were used to represent additional information such as time (Moffat et al., 2007; Papale and Valentini, 2003). By testing the structure of the artificial neural network, the network was built to be as simple as possible, and overfitting was avoided.

During the model training process, with the exception of the input and output layers, only 1 hidden layer was needed to obtain sufficient results; additional hidden layers did not improve model performance. In the output layer, a linear transfer function was used. Both the ANN and 
243

244

245

246

247

248

249

250

251

252

253

254

255

256

257

258

259

260

261

262

263

264

265

266

267

268

269

270

271

272

273

274

$\mathrm{RBF}$ were built using the input variables listed in Table 1, as well as the 30 -min data points of $\mathrm{F}_{\mathrm{C}}$, with the same parameters presented by Schmidt et al., 2007. The number of neurons in the ANN hidden layer was 5, and the number of neurons in the RBF hidden layer was 181.

\subsubsection{Regularized hierarchical linear regression model with Bayesian framework}

Since signals may be less pronounced than random errors, overfitting is a potential problem in regression models in which parameters estimate noise rather than the underlying signal. In earlier works, hierarchical modeling produced more accurate predictions than regular regression and also tended to reduce overfitting in the presence of a hierarchical data structure (Gelman, 2006). There have been some detailed examples highlighting uses of Bayesian and hierarchical Bayesian methods in plant physiology and ecosystem ecology (Ogle and Barber, 2008). Hierarchical modeling has been proposed to predict monthly streamflow (Lima and Lall, 2010) and extreme flooding (Lima et al., 2016). This study used varying intercepts of hierarchical modeling for the carbon flux data with a temporally hierarchical structure. The form of the model was as follows:

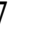

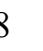

$$
\begin{aligned}
& \mathrm{y}_{i j} \sim N\left(\alpha_{j}+\beta x_{i j}, \sigma_{y}^{2}\right), \text { for } i=1, \ldots, 365 ; j=1, \ldots, 48, \\
& \alpha_{j} \sim N\left(\gamma_{j}, \sigma_{\alpha_{j}}^{2}\right), \\
& \beta \mid \sigma_{\beta}^{2} \sim N\left(0, \sigma_{\beta}^{2} \boldsymbol{I}\right),
\end{aligned}
$$

where $\mathrm{y}_{i j}$ is $\mathrm{F}_{\mathrm{C}}$ at time $j$ within Julian Day $i$, and $x_{i j}$ is a vector for the environmental measurement (Table 1) corresponding to $\mathrm{F}_{\mathrm{C}}$. The hyperparameters of the prior distribution of $\alpha_{j}$ are $\gamma_{j}$ and $\sigma_{\alpha_{j}}^{2}$. In previous studies, the prior ridge has been chosen for shrinking coefficients due to its weaker penalization of large coefficients (Fahrmeir et al., 2009). Therefore, we assumed that $\beta \mid \sigma_{\beta}^{2} \sim N(0$, $\left.\sigma_{\beta}^{2} \boldsymbol{I}\right)$

\subsubsection{Gaussian processes}

As nonlinear regression tools, Gaussian processes have nonparametric flexibility and can be used to fit arbitrary functions or surfaces (Azmy et al., 2009). Therefore, the Gaussian process is often used to replace the supervised neural network in nonlinear regression. The GP can be described by a mean function $m(x)$ (a vector) and a covariance function $k\left(x, x^{\prime}\right)$ (a matrix):

$$
f(x)=G P\left(m(x), k\left(x, x^{\prime}\right)\right)
$$

where $f(x)$ is a random variable. In this study, $f(x)$ was the modeled $\mathrm{F}_{\mathrm{C}}$. This assumes that the mean function $m(x)$ is equal to 0 since our data were standard normalized, and $k\left(x, x^{\prime}\right)$ is a function of the Euclidean distance between the predictors $x$ and $x^{\prime}$. The squared exponential covariance function was chosen with automatic relevance determination (Bishop, 2006): 


$$
\operatorname{cov}\left(f(x), f\left(x^{\prime}\right)\right)=k\left(x, x^{\prime}\right)=\sigma_{f}^{2} \exp \left(-\frac{1}{2} \sum_{i=1}^{D} \frac{\left\|x_{i}-x_{i}^{\prime}\right\|}{\sigma_{i}^{2}}\right),
$$

276 where $\sigma_{f}^{2}$ is a hyperparameter for the amplitude variance. The width hyperparameter $\sigma_{i}^{2}$ is separate

277 for each input variable $x_{i}$.

278

279

280

281

282

283

284

285

286

287

288

289

290

291

292

293

294

295

296

297

298

299

300

301

302

303

304

305

306

307

308

309

310

\subsection{Characteristics of random uncertainty}

The correlation between the predicted carbon flux and its corresponding residual is represented by Kendall's tau $(\tau)$ coefficient. If $\tau$ is close to 0 , the posterior residual does not contain structural error from the model. Conversely, if $\tau$ is close to 1 , the predicted value should contain the model structure error of the influence, and such interpretation information may be passed to the posterior residual (Wang et al., 2015).

The relationship between the standard deviation of the random uncertainty of carbon flux observations and the magnitude of the observed values is commonly expressed as follows:

$$
\sigma(\varepsilon)=a+b\left|F_{c}\right| .
$$

The intercept term $a$ varies from site to site, with a typical range of $0.9-3.5 \mu \mathrm{mol} \mathrm{m}^{-2} \mathrm{~s}^{-1}$ (Richardson et al., 2008). The larger the value of $a$, the greater the uncertainty. The range of the slope $b$ is usually $0.1-0.2$; the smaller the value of $b$, the closer the probability distribution of the uncertainty to white noise.

\subsection{Uncertainty in the cumulative carbon dioxide exchange}

To determine the random error of carbon flux and the error caused by interpolation, this study used the bootstrap method to estimate the deviation of the annual sum of ecosystem carbon exchange and its 95\% confidence interval. Estimating the root mean square error (RMSE), variance, and bias of the annual sum of carbon exchange required a complete carbon flux time series (1,000 bootstrap sequences). The variance of the total annual carbon exchange can be directly estimated, but due to vacancies in the carbon flux data, the deviation of the total annual carbon exchange cannot be directly estimated. To estimate the (potential) bias in carbon flux vacancy data, we used the bootstrap method to simulate and analyze the bias of high-quality modeling data in order to extend it to an annual scale (Richardson et al., 2006; Wang et al., 2015). The estimation steps used to determine the bias of the annual sum of carbon exchange were as follows:

(1) The vector $\hat{\varepsilon}$, which is the estimation of the random error $\varepsilon$, was estimated by subtracting the observed $\mathrm{F}_{\mathrm{C}}$ from the $\mathrm{F}_{\mathrm{C}}$ estimated by the models.

(2) All data (observed $F_{C}$ with gaps as well as modeled $F_{C}$ ) were divided in terms of the growing season, daytime, non-growing season, and nighttime. The daytime data of the growing season were divided according to the incident radiation intensity (limited to $400 \mathrm{~W} \cdot \mathrm{m}^{-2}$ ), resulting in 6 parts.

(3) $\hat{\varepsilon}$ was repeatedly sampled in order to obtain a new complete bias sequence (a total of 17,520 repeated extractions per year).

(4) A cumulated summation of the new complete bias sequence was calculated. 
311 (5) Steps (3) and (4) were repeated 1,000 times.

312 (6) The empirical distribution of the 1,000 biases of the annual sum of ecosystem carbon exchange, 313 along with the $95 \%$ confidence interval of the annual sum of carbon exchange, were estimated.

\section{Results}

\subsection{Carbon dioxide flux data characteristics}

To model the high-quality carbon flux data, the 30-min carbon flux data with high signal quality were screened. It can be seen that the flux observation points exhibit more obvious carbon uptake characteristics during the growing season (Fig. 3). To extract the nighttime flux error, the nighttime friction velocity thresholds for the growing and non-growing seasons were estimated, and the data on friction velocities less than the threshold were screened and eliminated. This amounted to approximately $2.4 \%$ of the data (415 data points). After processing for outliers and nighttime friction velocity threshold screening, approximately 35.9\% (or 6,293 observations) of the high-quality data remained, which was then used to build and test the model (Table 2). Among these measurements, there were 2,892 valid daytime observations $(\sim 16.5 \%)$ and 1,032 valid nighttime observations during the growing season $(\sim 5.9 \%)$. There were 1,583 valid daytime observations $(\sim 9 \%)$ and $786(\sim 4.5 \%)$ valid nighttime observations during the non-growing season.

Fig. 3. Mean diurnal courses of high-quality 30-min $\mathrm{F}_{\mathrm{C}}$ measurements averaged over 2-month periods after filtering: (a) Jan-Feb, (b) Mar-Apr, (c) May-Jun, (d) Jul-Aug, (e) Sep-Oct, and (f) Nov-Dec.

Within the boxes, the horizontal bars indicate medians, while the tops and bottoms of the boxes illustrate the $75^{\text {th }}$ and $25^{\text {th }}$ quartiles, respectively. Small circles represent outliers in the observations.

\section{Fig. 4. Histogram of the data gap distribution}

This study defined the length of time in which data were continuously missing as the missing time window. A histogram plot was used to display the distribution of the missing time window (Fig. 4). The average length of the missing time window for the flux data was $5.8 \mathrm{~h}$; a total of 24 missing time windows were longer than $24 \mathrm{~h}$, mainly concentrated in the non-growing season; the longest missing time window was 30 days (Fig. 5). It can be seen that wind speed and friction velocity $u^{*}$ differed significantly between the growing and non-growing seasons (Fig. 6). The details of the relationship between $u^{*}$ and wind speed using SMA regression are presented in Table 3 and Fig. 6c. The slopes of the SMA regression for the growing and non-growing seasons were not equal, indicating that the roughness index varied considerably with season.

Table 2. Quality control procedures for the 30-min flux data

Fig. 5. Time of $\mathrm{F}_{\mathrm{C}}$ and friction velocity $u^{*}$ observation times over the study year Red, orange, and gray represent $\mathrm{Qc}=0, \mathrm{Qc}=1$, and $\mathrm{Qc}=2$, respectively. 
The nighttime friction velocity threshold during the growing season was $0.12 \mathrm{~m} / \mathrm{s}$, and the corresponding value for the non-growing season was $0.10 \mathrm{~m} / \mathrm{s}$. Detailed information concerning the quality filtering procedures is listed in Table 2 . A total of 42 negative $F_{C}$ values were observed at night in this study, accounting for $1.9 \%$ of the nighttime data. After removal by the friction velocity threshold and other quality filtering procedures, the number of nighttime negative values was reduced to $16(\sim 0.7 \%)$.

Table 3. Standardized major axis estimation and statistical inference

Fig. 6. Values of nighttime friction velocity $u^{*}$ and wind speed

(a) Nighttime friction velocity $u^{*}$. (b) Nighttime wind speed. (c)The relationship between friction velocity and wind speed for all data was grouped by season. Green and gray represent the growing and non-growing seasons, respectively. Columns with different capital letters are significantly different $(\mathrm{p}<0.05)$ according to Fisher's least significant difference test.

\subsection{Results and residual analysis of gap-filling methods}

The results of the ANN, GP, HLM, RBF, and MDS methods are illustrated in Fig. 7. The test set $\mathrm{R}^{2}$ obtained by these different methods ranged from 0.77 to 0.84 and the RMSE ranged from 2.04 to $2.50 \mu \mathrm{mol} \mathrm{m} \mathrm{m}^{-2} \mathrm{~s}^{-1}$. There were differences in the $\mathrm{R}^{2}$ and RMSE obtained by these methods. The GP and MDS methods represented the full range of scatter in the observations, while the others all exhibited the upper and lower limits (Fig. 7). The training set fit curve overlapped with the test set fit curve, and they were equally close to the 1:1 line, indicating that there was no overfitting phenomenon in these methods. The gap-filled $\mathrm{F}_{\mathrm{C}}$ for the five methods exhibited a relatively obvious diurnal variation (Fig. 8).

Fig. 7. Training and test performances of the models for the dataset with 6,293 points

(a)ANN, (b)GP, (c)HLM, (d)RBF, (e) MDS. For comparison, the plotted lines consist of the training fit (solid black line), the test fit (green dotted line), and the 1:1 line (solid red). Units

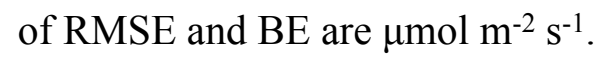

Fig. 8. Fingerprints of the complete $F_{C}$ gap-filled by the (a) ANN, (b) GP, (c) HLM, (d) RBF, and (e) MDS methods

When model error is quantified, the model residuals can quantify the random uncertainty. In this study, it was assumed that model error was negligible. Thus, the model residuals could be attributed almost entirely to random error. The empirical distribution of the model residuals and the fitted curves (Fig. 9) can describe the uncertainty of the random error and largely reflects the nature of the carbon flux observations. The model residual distributions obtained by the five methods exhibited characteristics of sharp peaks and thick tails, indicating non-normality. Comparing the kurtosis for the empirical distributions of the residuals obtained by these methods (Fig. 9), it was found that GP $>$ MDS $>$ ANN $>$ HLM $>$ RBF. Additionally, the empirical 
381 distribution of these residuals was discovered to approximate the Laplace (or double-exponential) 382 distribution by the Wilcoxon rank sum test $(\mathrm{p}>0.05)$.

Fig. 9. Empirical distributions of the residuals predicted by the five gap-filling methods and their corresponding Laplacian distributions

(a)ANN, (b)GP, (c)HLM, (d)RBF, (e)MDS.

Comparing the correlations between the carbon flux observations and the corresponding residuals obtained by the 5 different methods (Table 4), it was found that during the day in the non-growing season, $\mathrm{Rd} \leq 400 \mathrm{~W} \mathrm{~m}^{-2}$ showed a significant weak positive correlation; the same was true at night in the non-growing season. Additionally, it was shown that the random uncertainty during the non-growing season increased with increasing carbon flux. The correlations between the flux prediction values and the residuals obtained by the 5 methods differed during the growing season. In the growing season, the GP and MDS methods each exhibited a significant positive correlation, while the other methods showed either a relatively weak correlation ( $\tau$ close to 0 ) or no significant correlation.

Table 4. Kendall's tau $(\tau)$ coefficient between the 5 different methods of carbon flux prediction and the corresponding residuals

The standard deviation of the random flux measurement error varied linearly with the magnitude of the $\mathrm{F}_{\mathrm{C}}$. Results are summarized in Table 5. The range of the intercept term $a$ of the flux observation station in this study was $1.3209-1.5550 \mu \mathrm{mol} \mathrm{m}^{-2} \mathrm{~s}^{-1}$, which is within the typical range. The largest values came from the MDS method; the smallest from the GP. The uncertainties of the carbon flux gap-filling from these 5 methods were ranked as follows: GP < ANN $<$ RBF $<$ HLM $<$ MDS. The slope $b$ ranged from 0.0579-0.1092, which was slightly less than the typical range. The smallest slope came from the HLM; the largest from the MDS. The posterior residual of the carbon flux gap-filling from the HLM method was closer to white noise than that from the MDS method. The carbon flux data gaps were filled by the different methods. The probability distributions of the measured random errors varied with changes in the different gap-filling methods; the gap-filling methods also affected the estimation of the annual sum of carbon dioxide exchange.

Table 5. Relationship between the magnitude of carbon flux and the standard deviation of random uncertainty

\subsection{Annual sum of carbon dioxide exchange}

Utilizing the gap-filling from the 5 methods, the complete carbon flux data were obtained. As shown in Table 6, the gap-filled annual $\mathrm{F}_{\mathrm{C}}$ sums from $\mathrm{MC}$ simulations were estimated to be $159.91 \pm 18.35 \mathrm{~g} \mathrm{C} \mathrm{m}^{-2} \mathrm{yr}^{-1}$ for ANN, $-178.25 \pm 8.01 \mathrm{~g} \mathrm{C} \mathrm{m}^{-2} \mathrm{yr}^{-1}$ for $\mathrm{GP},-167.16 \pm 19.08 \mathrm{~g} \mathrm{C} \mathrm{m}^{-}$ ${ }^{2} \mathrm{yr}^{-1}$ for RBF, $-156.95 \pm 3.15 \mathrm{~g} \mathrm{C} \mathrm{m}^{-2} \mathrm{yr}^{-1}$ for HLM, and $-155.21 \pm 5.16 \mathrm{~g} \mathrm{C} \mathrm{m}^{-2} \mathrm{yr}^{-1}$ for MDS. The $\mathrm{CO}_{2}$ exchange sums from $\mathrm{MC}$ simulations for the growing and non-growing seasons are listed in 
417 Table 7. Given that five different gap-filling models were used, it was definitely necessary to 418 correct the model error. Based on the chosen fusion method (Kuncheva, 2002), it was assumed 419 that the mean of the 5 methods was close to the true value of the annual sum of carbon dioxide 420 exchange. The annual sum of $\mathrm{CO}_{2}$ exchange in 2015 at the observed site was estimated to be $421 \quad 163.50 \pm 9.43 \mathrm{~g} \mathrm{C} \mathrm{m}^{-2} \mathrm{yr}^{-1}$, indicating that the desert Tugai forest in the Ebinur Lake Basin is a net 422 carbon sink on an annual basis.

Table 6. Annual sum and deviation of the $\mathrm{CO}_{2}$ exchange estimated by the different methods

Table 7. Seasonal sum of $\mathrm{CO}_{2}$ exchange estimated by the different methods

425

426

427

428

429

430

431

432

433

434

435

The averages of the annual sum of $\mathrm{CO}_{2}$ exchange obtained by the 5 methods ranged from 178.25 to $-155.21 \mathrm{~g} \mathrm{C} \mathrm{m}^{-2} \mathrm{yr}^{-1}$, and the standard deviation ranged from 3.15-19.08 $\mathrm{g} \mathrm{C} \mathrm{m}^{-2} \mathrm{yr}^{-1}$ (Table 6). The smallest (in terms of absolute value) came from the MDS method, and the largest from the RBF. The average bias of the annual sum of ecosystem carbon exchange for the 5 methods ranged from -13.69 to $14.05 \mathrm{~g} \mathrm{C} \mathrm{m}^{-2} \mathrm{yr}^{-1}$. The HLM and MDS tended to underestimate, while the other methods tended to overestimate (Table 6). The smallest mean bias of the annual sum of carbon exchange came from the ANN; the largest was from the RBF. The GP had the smallest 95\% confidence interval for the bias of the annual sum of carbon dioxide exchange, while the HLM had the largest. Comparing the carbon accumulation losses of ecosystems estimated by the different methods (Fig. 10), it was found that these five methods exhibited a consistent performance during the growing season and large differences during the non-growing season.

Fig. 10. Cumulative carbon dioxide exchange obtained by the different methods

The data sources were composed of 3 parts, which were high-quality modeling data, data used to calculate annual sum of carbon dioxide exchange, and predictions from the different gapfilling methods.

\section{Discussion}

\subsection{Differences in annual sums of $\mathrm{CO}_{2}$ exchange among gap-filling methods for the Tugai forest}

The annual sum of carbon dioxide exchange from the Tugai forest in our study was estimated to range from -178.25 to $-155.21 \mathrm{~g} \mathrm{C} \mathrm{m}^{-2} \mathrm{yr}^{-1}$. In a previous study, a total annual carbon exchange ranging from -155 to $-55 \mathrm{~g} \mathrm{C} \mathrm{m}^{-2} \mathrm{yr}^{-1}$ for oak/grass savanna from 2000-2006 was obtained (Ma et al., 2007), slightly less than the estimated value in this investigation. For comparison, Wohlfahrt et al. (2008) reported a net sink from 102 to $110 \mathrm{~g} \mathrm{C} \mathrm{m}^{-2} \mathrm{yr}^{-1}$ in the Mojave desert ecosystem. For a desert shrub community in Baja California/Mexico, the total annual carbon dioxide exchange was determined to range from -52 to $-39 \mathrm{~g} \mathrm{C} \mathrm{m}^{-2} \mathrm{yr}^{-1}$ (Hastings et al., 2005). In a riparian forest with similar mean annual temperature and precipitation, Ma et al. (2017) reported a net carbon sink from $278 \mathrm{~g} \mathrm{C} \mathrm{m}^{-2} \mathrm{yr}^{-1}$ to $427 \mathrm{~g} \mathrm{C} \mathrm{m}^{-2} \mathrm{yr}^{-1}$. Thus, the carbon sink capacity of the Tugai forest in the Ebinur Lake Basin is higher than that of the savanna in the Mojave Desert ecosystem of California and the desert shrub in Baja California/Mexico, while lower than the riparian forest. 
The performances of the gap-filling methods in this study were comparatively good. It is difficult to determine the best applicability of the gap-filling methods in the desert Tugai forest via a single statistical parameter. Therefore, this study comprehensively evaluated the gap-filling models using $\mathrm{R}^{2}$, RMSE, and BE. It was found that the test set $\mathrm{R}^{2}$ obtained by the ANN method was 0.827 . The test set $\mathrm{R}^{2}$ obtained by Menzer et al. (2015) using the ANN method was 0.740, which was $8 \%$ lower than this study. The $\mathrm{R}^{2}$ value obtained by the GP method was 0.844 , which was $6 \%$ higher than that of Menzer et al. (2015); $\mathrm{R}^{2}$ obtained by the RBF method was 0.790 , which was 39\% higher than that of Lärvi et al. (2012) and 3\% higher than that of Menzer et al. (2015). The RMSE of the test set obtained by the 5 methods ranged from $2.04-2.50 \mu \mathrm{mol} \mathrm{m} \mathrm{m}^{-2} \mathrm{~s}^{-1}$, which was smaller than that of Lärvi et al. (2012) and Menzer et al. (2015). This may be primarily due to the fact that the estimations by Lärvi et al. (2012) and Menzer et al. (2015) were conducted on urban ecosystems in which the underlying surface of the observation sites was rougher, and the environmental factors affecting carbon dioxide exchange were more complex. Although the eddy covariance method requires that the underlying surface be uniform and flat, the position of the terrain is not absolutely guaranteed in the actual selection process of the underlying surface. In addition, when screening the modeling data, data with a signal quality of 2 were excluded (Järvi et al., 2012). In the current study, however, all data with a signal quality other than 0 (including 1 and 2) were excluded, resulting in high modeling data quality. It is clear that the selection of modeling data is particularly important when training models.

There were minor differences among the standard deviations of the annual sum of carbon dioxide exchange obtained by the 5 methods. Due to the low annual sum of arid desert ecosystem carbon dioxide exchange, its estimation is sensitive to data processing methods, with some methods possibly leading to bias (Liu et al., 2010). In addition, the soil volume water content data were distorted as a result of the high degree of soil salinization. Therefore, this study ignored the impact of soil moisture on carbon dioxide flux, leading to a very large difference in the annual sum of carbon dioxide exchange obtained by the 5 methods. It should be noted that this study was limited to the seasonal signal from only a single year's worth of data at the site. Future studies should utilize a longer dataset, which would provide more insight into the ecological functioning of the site.

The bias error of the annual sum of carbon dioxide exchange obtained by the 5 methods ranged from -13.69 to $14.05 \mathrm{~g} \mathrm{C} \mathrm{m}^{-2} \mathrm{yr}^{-1}$. The minor differences found in the bias error may be related to the fact that the carbon source/sink function of the Tugai forest is more affected by environmental factors than that of other ecosystems, especially soil moisture content. The impact of data processing methods on the estimation of the annual sum of carbon dioxide exchange was discovered to be highly variable, which may be related to the sensitivity of arid desert ecosystems to environmental factors, as well as the definition of valid data.

\subsection{Carbon dioxide exchange during nighttime and non-growing season daytime}

This study used a quantile-based method to determine the outliers, and also identified and deleted the anomalies in the $\mathrm{F}_{\mathrm{C}}$ time series. After careful screening during data preprocessing, a total of 42 negative values of carbon dioxide exchange at night were observed, accounting for 
493

494

$1.9 \%$ of the nighttime data, which was far less than the $28 \%$ of temperate broadleaf forest observations (Thomas et al., 2011). The negative carbon flux observations indicate that there was carbon uptake in the underlying vegetation of the flux tower at night, although this phenomenon was unlikely (Thomas et al., 2011). There is currently no unified view to explain this phenomenon, ignoring atmospheric advection and precipitation as possible causes. Moreover, there is also a systematic error that stems from ignoring the atmospheric advection and precipitation measurements. Even though advection correction is attractive from a theoretical point of view, it is unlikely that air advection characteristics varied over the observed period and sites (Feigenwinter et al., 2008).

The accumulation of carbon dioxide exchange obtained by the 5 different methods performed consistently during the growing season and exhibited very large differences during the nongrowing season (Fig. 10). During the growing season, the carbon flux data were relatively complete, with no long gaps; the carbon flux data during the non-growing season, however, had more gaps, and the continuously missing time windows were long (Fig. 5), leading to very large differences in method performance. The five methods displayed obvious carbon uptake characteristics in February (Fig. 10), which was consistent with the daily variation characteristics of the selected high-quality modeling data from January and February (Fig. 3a). This result may have been influenced by ignoring the advection and storage terms, which produced a certain systematic error (Bowling et al., 2010). In addition, the high saline alkali water and soil played an important role in the carbon uptake (Li et al., 2015; Ma et al. 2013; Xie et al. 2009).

To some extent, the valid data observed at the site depend on independent processes influenced by the geographic environment of the observatory. The resulting uncertainty is primarily random, depending on both the missing time window and the gap-filling method. The friction velocity $u^{*}$ is intended to capture the turbulent characteristics in the vicinity of the surface. Nighttime data under unsteady conditions are often removed by $u^{*}$ threshold screening. Each site has a specific $u^{*}$ threshold that is expected to vary over time (Béziat et al., 2009; Moureaux et al., 2008). The nighttime friction velocity threshold $(0.12 \mathrm{~m} / \mathrm{s})$ during the growing season was greater than the corresponding value for the non-growing season $(0.10 \mathrm{~m} / \mathrm{s})$, indicating that the flux observation station experienced different air turbulence characteristics during different seasons (Fig. 6). A possible reason for this is simply that the air temperature during the growing season is higher than during the non-growing season. According to the turbulence intensity theorem, the turbulence intensity is a function of both velocity and temperature shears ( $\mathrm{Hu}$ et al., 2007). The near-surface temperature changes more rapidly during the growing season night than during the non-growing season night. Thus, in the near-surface layer, the temperature shear formed during the growing season night is larger than that formed during the non-growing season night. In addition, due to vegetation growth, the underlying surface roughness of the observatory is higher during the non-growing season than during the growing season (Fig. 6c). Uncertainty may still exist after $u^{*}$ threshold screening. There is no guarantee that the data screening process will eliminate all bad data, nor that only bad data will be removed.

\subsection{Uncertainty analysis}


All measurements have errors or uncertainties (Taylor 1997), and measurement uncertainty includes random and systematic uncertainties (ISO/IEC 2008). Systematic error is considered to be a constant but unknown deviation (Abernethy et al., 1985) and must be estimated by empirical, theoretical, or supplementary measurements. Systematic error cannot be determined by statistical analysis of the measured data itself, nor can it be reduced by averaging. The bootstrapping method has been used to quantify the random uncertainty of the flux integral at different time scales (Wang et al., 2015). In addition, the Monte Carlo method is used to estimate the transmission of uncertainty over longer time scales, particularly the uncertainty associated with gap filling (Moffat et al., 2007).

Comparing the change in the empirical distribution of the residuals obtained by the five gapfilling methods (Fig. 9), it was discovered that the empirical distribution of these residuals approximated the Laplace (or double-exponential) distribution. Actually, the distribution of the $\mathrm{F}_{\mathrm{C}}$ random error from the Tugai forest $\left(\left|\mathrm{F}_{\mathrm{C}}\right|<10 \mu \mathrm{mol} \mathrm{m}^{-2} \mathrm{~s}^{-1}\right)$ is leptokurtic. As a characteristic of random uncertainty, the leptokurtic distribution has been shown to be robust across a variety of sites and ecosystem types (Hollinger and Richardson, 2005; Richardson et al., 2008; Stauch et al., 2008; Lasslop et al., 2008; Liu et al., 2008; Wang et al., 2015). It has been suggested that the leptokurtic distribution is the result of a superposition of Gaussian distributions and a non-constant variance (Hollinger et al., 2004; Lasslop et al., 2008). After normalizing the error (i.e., dividing each flux observation by the expected standard deviation), its distribution approximated a Gaussian distribution (Richardson et al., 2008).

We also found that the random uncertainty increased with increasing carbon flux (Table 5). This was consistent with the findings of Richardson et al. (2008) for the uncertainty of carbon flux measurements from model residuals. Using different methods to fill gaps leads to the differences among the distributions of the measured random errors and affects the estimation of the annual sum of carbon dioxide exchanges. Considering the differences in site characteristics and types of ecosystems, as well as the degree to which the valid flux data are contaminated with data from a separate (nonbiological or atmospheric) process, it is necessary to evaluate random uncertainty carefully and site specifically. This study may provide a valid method for evaluating the gap-filling uncertainty of other types of ecosystems.

\section{Conclusions}

This study estimated the annual sum of carbon dioxide exchange of the Tugai forest in the Ebinur Lake Basin of Northwest China in 2015. Selective system errors were corrected by determining the friction velocity threshold and utilizing it to extract high-quality data on the growing and non-growing seasons. Five different methods were used to fill the gaps in the carbon flux time series. These methods all exhibited higher $\mathrm{R}^{2}$ and lower RMSE values than previous techniques. The GP method was the best of these gap-filling techniques. Uncertainty was inferred from the model residuals; the distribution of the residuals exhibited non-normal properties of spikes and thick tails. The ultimate goal of this investigation was not to select the best gap-filling method by comparing the merits of each but to estimate the uncertainty caused by the gap-filling and to correct model error. The total annual carbon exchange of the Tugai forest at the observation 
573 site in 2015 was $-163.50 \pm 9.43 \mathrm{~g} \mathrm{C} \mathrm{m}^{-2} \mathrm{yr}^{-1}$, indicating that the Tugai forest in the Ebinur Lake 574 Basin is a carbon sink. The errors from different sources were complex, making it difficult to give 575 accurate estimates; therefore, this study only estimated the random errors and bias. Estimating 576 errors from different sources will be the focus of uncertainty studies on the cumulants of carbon 577 dioxide exchange in the future. Exploring the function of the Tugai forest in arid regions still 578 requires additional understanding of the underlying ecological mechanisms.

579 Acknowledgments: This research was supported by the National Natural Science Foundation of 580 China (No. 31560131). We thank LetPub (www.letpub.com) for its linguistic assistance during the 581 preparation of this manuscript.

\section{References}

Abernethy R, Benedict R, and Dowdell R. 1985. ASME measurement uncertainty. Journal of Fluids Engineering 107:161.

Aubinet M, and Feigenwinter C. 2010. Direct $\mathrm{CO}_{2}$ advection measurements and the night flux problem. Agricultural and Forest Meteorology 150:651-654. 10.1016/j.agrformet.2010.03.007

Azmy WM, El Gayar N, Atiya AF, and El-Shishiny H. 2009. MLP, Gaussian Processes and Negative Correlation Learning for Time Series Prediction. Multiple Classifier Systems, Proceedings 5519:428-+.

Baldocchi D. 2014. Measuring fluxes of trace gases and energy between ecosystems and the atmosphere - the state and future of the eddy covariance method. Global Change Biology 20:3600-3609. 10.1111/gcb.12649

Baldocchi D, Chu HS, and Reichstein M. 2018. Inter-annual variability of net and gross ecosystem carbon fluxes: A review. Agricultural and Forest Meteorology 249:520-533. 10.1016/j.agrformet.2017.05.015Béziat P, Ceschia E, and Dedieu G. 2009. Carbon balance of a three crop succession over two cropland sites in South West France. Agricultural and Forest Meteorology 149:1628-1645.

Bishop CM. 2006. Pattern Recognition and Machine Learning (Information Science and Statistics).

Bowling DR, Bethers-Marchetti S, Lunch CK, Grote EE, and Belnap J. 2010. Carbon, water, and energy fluxes in a semiarid cold desert grassland during and following multiyear drought. Journal of Geophysical Research 115. 10.1029/2010jg001322

Braswell BH, Sacks WJ, Linder E, and Schimel DS. 2005. Estimating diurnal to annual ecosystem parameters by synthesis of a carbon flux model with eddy covariance net ecosystem exchange observations. Global Change Biology 11:335-355. 10.1111/j.1365-2486.2005.00897.x

Desai AR, Bolstad PV, Cook BD, Davis KJ, and Carey EV. 2005. Comparing net ecosystem exchange of carbon dioxide between an old-growth and mature forest in the upper Midwest, USA. Agricultural and Forest Meteorology 128:33-55. 10.1016/j.agrformet.2004.09.005

Donohue RJ, Roderick ML, McVicar TR, and Farquhar GD. 2013. Impact of $\mathrm{CO}_{2}$ fertilization on maximum foliage cover across the globe's warm, arid environments. Geophysical Research Letters 40:3031-3035. $10.1002 /$ grl.50563

Fahrmeir L, Kneib T, and Konrath S. 2009. Bayesian regularisation in structured additive regression: a unifying perspective on shrinkage, smoothing and predictor selection. Statistics and Computing 20:203-219. 10.1007/s11222-009-9158-3

Falge E, Baldocchi D, Olson R, Anthoni P, Aubinet M, Bernhofer C, Burba G, Ceulemans R, Clement R, Dolman H, Granier A, Gross P, Grunwald T, Hollinger D, Jensen NO, Katul G, Keronen P, Kowalski A, Lai CT, Law 
613

614

615

616

617

618

619

620

621

622

623

624

625

626

627

628

629

630

631

632

633

634

635

636

637

638

639

640

641

642

643

644

645

646

647

648

649

650

651

652

653

BE, Meyers T, Moncrieff H, Moors E, Munger JW, Pilegaard K, Rannik U, Rebmann C, Suyker A, Tenhunen J, Tu K, Verma S, Vesala T, Wilson K, and Wofsy S. 2001. Gap filling strategies for defensible annual sums of net ecosystem exchange. Agricultural and Forest Meteorology 107:43-69. Doi 10.1016/S01681923(00)00225-2

Feigenwinter C, Bernhofer C, Eichelmann U, Heinesch B, Hertel M, Janous D, Kolle O, Lagergren F, Lindroth A, Minerbi S, Moderow U, Mölder M, Montagnani L, Queck R, Rebmann C, Vestin P, Yernaux M, Zeri M, Ziegler W, and Aubinet M. 2008. Comparison of horizontal and vertical advective $\mathrm{CO}_{2}$ fluxes at three forest sites. Agricultural and Forest Meteorology 148:12-24. 10.1016/j.agrformet.2007.08.013

Foken T, and Wichura B. 1996. Tools for quality assessment of surface-based flux measurements. Agricultural \& Forest Meteorology 78:83-105.

Gelman, and Andrew. 2006. Multilevel (Hierarchical) Modeling: What It Can and Cannot Do. Technometrics 48:432435.

Gove JH, and Hollinger DY. 2006. Application of a dual unscented Kalman filter for simultaneous state and parameter estimation in problems of surface-atmosphere exchange. Journal of Geophysical Research 111. $10.1029 / 2005 \mathrm{jd} 006021$

Hagen SC, Braswell BH, Linder E, Frolking S, Richardson AD, and Hollinger DY. 2006. Statistical uncertainty of eddy flux-based estimates of gross ecosystem carbon exchange at Howland Forest, Maine. Journal of Geophysical Research.

Hastings SJ, Oechel WC, and Muhlia-Melo A. 2005. Diurnal, seasonal and annual variation in the net ecosystem $\mathrm{CO}_{2}$ exchange of a desert shrub community (Sarcocaulescent) in Baja California, Mexico. Global Change Biology 11:927-939. 10.1111/j.1365-2486.2005.00951.x

He X, Lv G, and Qin L. 2014. Research on data characteristics during non-growing season of desert-wetland ecosystem in Ebinur Lake. Acta Ecologica Sinica 34:6655-6665.

He X, Lv G, Qin L, Chang S, Yang M, Yang J, and Yang X. 2015. Effects of Simulated Nitrogen Deposition on Soil Respiration in a Populus euphratica Community in the Ebinur Lake Area, a Desert Ecosystem of Northwestern China. Plos One 10:e137827.

Hollinger DY, Aber J, Dail B, Davidson EA, Goltz SM, Hughes H, Leclerc MY, Lee JT, Richardson AD, Rodrigues C, Scott NA, Achuatavarier D, and Walsh J. 2004. Spatial and temporal variability in forest-atmosphere $\mathrm{CO}_{2}$ exchange. Global Change Biology 10:1689-1706. 10.1111/j.1365-2486.2004.00847.x

Hollinger DY, and Richardson AD. 2005. Uncertainty in eddy covariance measurements and its application to physiological models. Tree Physiology 25:873-885. DOI 10.1093/treephys/25.7.873

$\mathrm{Hu}$ Y, Chen J, and Zuo H. 2007. Theorem of turbulent intensity and macroscopic mechanism of the turbulence development. Science in China Series D: Earth Sciences 50:789-800.

$\mathrm{Hu}$ Y, Chen J, and Zuo H. 2007. Theorem of turbulent intensity and macroscopic mechanism of the turbulence development. Science in China Series D: Earth Sciences 50:789-800.

Järvi L, Nordbo A, Junninen H, Riikonen A, Moilanen J, Nikinmaa E, and Vesala T. 2012. Seasonal and annual variation of carbon dioxide surface fluxes in Helsinki, Finland, in 2006-2010. Atmospheric Chemistry and Physics Discussions 12:8355-8396. 10.5194/acpd-12-8355-2012

Jasoni RL, Smith SD, and III JAA. 2005. Net ecosystem $\mathrm{CO}_{2}$ exchange in Mojave Desert shrublands during the eighth year of exposure to elevated $\mathrm{CO}_{2}$. Global Change Biology 11:749-756.

Jin H, Bai X, Man Z, and Zan M. 2010. Space difference of soil in Xinjiang Ebinur Lake Wetland Natural Reserve

Peer) reviewing PDF | (2019:07:39610:3:0:NEW 20 Dec 2019) 
654

655

656

657

658

659

660

661

662

663

664

665

666

667

668

669

670

671

672

673

674

675

676

677

678

679

680

681

682

683

684

685

686

687

688

689

690

691

692

693

694

District. Journal of Arid Land Resources and Environment 2:150-157.

Kormann R, and Meixner FX. 2001. An analytical footprint model for non-neutral stratification. Boundary-Layer Meteorology 99:207-224. Doi 10.1023/A:1018991015119

Kuncheva LI. 2002. A theoretical study on six classifier fusion strategies. IEEE Transactions on pattern analysis and machine intelligence 24:281-286.

Kunwor S, Starr G, Loescher HW, and Staudhammer CL. 2017. Preserving the variance in imputed eddy-covariance measurements: Alternative methods for defensible gap filling. Agricultural and Forest Meteorology 232:635649. 10.1016/j.agrformet.2016.10.018

Lasslop G, Reichstein M, Kattge J, and Papale D. 2008. Influences of observation errors in eddy flux data on inverse model parameter estimation. Biogeosciences Discussions 5:751-785.

Li S, Asanuma J, Eugster W, Kotani A, Liu J, Urano T, Oikawa T, Davaa G, Oyunbaatar D, and Sugita M. 2005. Net ecosystem carbon dioxide exchange over grazed steppe in central Mongolia. Global Change Biology 11:1941-1955.

Li Y, Wang Y-G, Houghton RA, and Tang L-S. 2015. Hidden carbon sink beneath desert. Geophysical Research Letters 42:5880-5887. 10.1002/2015g1064222

Lima CHR, and Lall U. 2010. Spatial scaling in a changing climate: A hierarchical bayesian model for non-stationary multi-site annual maximum and monthly streamflow. Journal of Hydrology 383:307-318.

Lima CHR, Lall U, Troy T, and Devineni N. 2016. A hierarchical Bayesian GEV model for improving local and regional flood quantile estimates. Journal of Hydrology 541:816-823.

Liu M, He H, Yu G, Luo Y, Sun X, and Wang H. 2008. Uncertainty analysis of $\mathrm{CO}_{2}$ flux components in subtropical evergreen coniferous plantation. Science in China Series D: Earth Sciences 52:257-268. 10.1007/s11430009-0010-6

Liu M, He H, Yu G, Sun X, Zhu X, Zhang L, Zhao X, Wang H, Shi P, and Han S. 2010. Impacts of uncertainty in data processing on estimation of $\mathrm{CO}_{2}$ flux components. Chinese Journal of Applied Ecology 21:2389-2396.

Ma J, Wang ZY, Stevenson BA, Zheng XJ, and Li Y. 2013. An inorganic $\mathrm{CO}_{2}$ diffusion and dissolution process explains negative $\mathrm{CO}_{2}$ fluxes in saline/alkaline soils. Scientific Reports 3:2025. 10.1038/srep02025

Ma J, Liu R, Tang L-S, Lan Z-D, and Li Y. 2014. A downward $\mathrm{CO}_{2}$ flux seems to have nowhere to go. Biogeosciences Discussions 11:6251-6262.

Ma S, Baldocchi DD, Xu L, and Hehn T. 2007. Inter-annual variability in carbon dioxide exchange of an oak/grass savanna and open grassland in California. Agricultural \& Forest Meteorology 147:157-171.

Ma X, Feng Q, Yu T, Su Y, and Deo R. 2017. Carbon Dioxide Fluxes and Their Environmental Controls in a Riparian Forest within the Hyper-Arid Region of Northwest China. Forests 8. 10.3390/f8100379

Massman W J, Lee X, Eddy Covariance Flux Corrections and Uncertainties in Long Term Studies of Carbon and Energy Exchanges. Agricultural and Forest Meteorology 113:121-144.

Mauder M, Cuntz M, Drüe C, Graf A, Rebmann C, Schmid HP, Schmidt M, and Steinbrecher R. 2013. A strategy for quality and uncertainty assessment of long-term eddy-covariance measurements. Agricultural \& Forest Meteorology 169:122-135.

Menzer O, Meiring W, Kyriakidis PC, and McFadden JP. 2015. Annual sums of carbon dioxide exchange over a heterogeneous urban landscape through machine learning based gap-filling. Atmospheric Environment 101:312-327. 10.1016/j.atmosenv.2014.11.006

Menzer O, Moffat AM, Meiring W, Lasslop G, Schukat-Talamazzini EG, and Reichstein M. 2013. Random errors in 
695

696

697

698

699

700

701

702

703

704

705

706

707

708

709

710

711

712

713

714

715

716

717

718

719

720

721

722

723

724

725

726

727

728

729

730

731

732

733

734

735 carbon and water vapor fluxes assessed with Gaussian Processes. Agricultural and Forest Meteorology 178:161-172. 10.1016/j.agrformet.2013.04.024

Moffat AM, Papale D, Reichstein M, Hollinger DY, Richardson AD, Barr AG, Beckstein C, Braswell BH, Churkina G, Desai AR, Falge E, Gove JH, Heimann M, Hui D, Jarvis AJ, Kattge J, Noormets A, and Stauch VJ. 2007. Comprehensive comparison of gap-filling techniques for eddy covariance net carbon fluxes. Agricultural and Forest Meteorology 147:209-232. 10.1016/j.agrformet.2007.08.011

Moureaux C, Debacq A, Hoyaux J, Suleau M, Tourneur D, Vancutsem F, Bodson B, and Aubinet M. 2008. Carbon balance assessment of a Belgian winter wheat crop (Triticum aestivum L.). Global Change Biology 14:13531366.

Munir TM, Perkins M, Kaing E, and Strack M. 2015. Carbon dioxide flux and net primary production of a boreal treed bog: Responses to warming and water-table-lowering simulations of climate change. Biogeosciences 12:121.

Ogle K, and Barber JJ. 2008. Bayesian Data-Model Integration in Plant Physiological and Ecosystem Ecology. Progress in Botany 69:281-311.

Papale D, Reichstein M, Aubinet M, Canfora E, Bernhofer C, Kutsch W, Longdoz B, Rambal S, Valentini R, Vesala T, and Yakir D. 2006. Towards a standardized processing of Net Ecosystem Exchange measured with eddy covariance technique: algorithms and uncertainty estimation. Biogeosciences 3:571-583. DOI 10.5194/bg-3$571-2006$

Papale D, and Valentini R. 2003. A new assessment of European forests carbon exchanges by eddy fluxes and artificial neural network spatialization. Global Change Biology 9:525-535. DOI 10.1046/j.1365-2486.2003.00609.x

Poulter B, Frank D, Ciais P, Myneni RB, Andela N, Bi J, Broquet G, Canadell JG, Chevallier F, and Liu YY. 2014. Contribution of semi-arid ecosystems to interannual variability of the global carbon cycle. Nature 509:600.

Rebane S, Jõgiste K, Põldveer E, Stanturf JA, and Metslaid M. 2019. Direct measurements of carbon exchange at forest disturbance sites: a review of results with the eddy covariance method. Scandinavian Journal of Forest Research:1-13. 10.1080/02827581.2019.1659849

Reichstein M, Falge E, Baldocchi D, Papale D, Aubinet M, Berbigier P, Bernhofer C, Buchmann N, Gilmanov T, Granier A, Grünwald T, Havránková K, Ilvesniemi H, Janous D, Knohl A, Laurila T, Lohila A, Loustau D, Matteucci G, Meyers T, Miglietta F, Ourcival J-M, Pumpanen J, Rambal S, Rotenberg E, Sanz M, Tenhunen J, Seufert G, Vaccari F, Vesala T, Yakir D, and Valentini R. 2005. On the separation of net ecosystem exchange into assimilation and ecosystem respiration: review and improved algorithm. Global Change Biology 11:1424-1439. 10.1111/j.1365-2486.2005.001002.x

Richardson AD, Hollinger DY, Burba GG, Davis KJ, Flanagan LB, Katul GG, William Munger J, Ricciuto DM, Stoy PC, Suyker AE, Verma SB, and Wofsy SC. 2006. A multi-site analysis of random error in tower-based measurements of carbon and energy fluxes. Agricultural and Forest Meteorology 136:1-18. 10.1016/j.agrformet.2006.01.007

Richardson AD, Mahecha MD, Falge E, Kattge J, Moffat AM, Papale D, Reichstein M, Stauch VJ, Braswell BH, Churkina G, Kruijt B, and Hollinger DY. 2008. Statistical properties of random $\mathrm{CO}_{2}$ flux measurement uncertainty inferred from model residuals. Agricultural and Forest Meteorology 148:38-50. 10.1016/j.agrformet.2007.09.001

Ruppert J, Mauder M, Thomas C, and Lüers J. 2006. Innovative gap-filling strategy for annual sums of $\mathrm{CO}_{2}$ net ecosystem exchange. Agricultural and Forest Meteorology 138:5-18. 10.1016/j.agrformet.2006.03.003

Peer] reviewing PDF | (2019:07:39610:3:0:NEW 20 Dec 2019) 
Schmidt A, Wrzesinsky T, and Klemm O. 2007. Gap Filling and Quality Assessment of $\mathrm{CO}_{2}$ and Water Vapour Fluxes above an Urban Area with Radial Basis Function Neural Networks. Boundary-Layer Meteorology 126:389413. 10.1007/s10546-007-9249-7

Soloway AD, Amiro BD, Dunn AL, and Wofsy SC. 2017. Carbon neutral or a sink? Uncertainty caused by gap-filling long-term flux measurements for an old-growth boreal black spruce forest. Agricultural and Forest Meteorology 233:110-121. 10.1016/j.agrformet.2016.11.005

Stauch VJ, Jarvis AJ, and Schulz K. 2008. Estimation of net carbon exchange using eddy covariance $\mathrm{CO}_{2}$ flux observations and a stochastic model. Journal of Geophysical Research 113. 10.1029/2007jd008603

Stone R. 2008. Have Desert Researchers Discovered a Hidden Loop in the Carbon Cycle? Science 320:1409-1410. Taylor J. 1997. Introduction to error analysis, the study of uncertainties in physical measurements.

Thomas MV, Malhi Y, Fenn KM, Fisher JB, Morecroft MD, Lloyd CR, Taylor ME, and McNeil DD. 2011. Carbon dioxide fluxes over an ancient broadleaved deciduous woodland in southern England. Biogeosciences 8:1595-1613.

Wang H, Cai Y, Yang Q, Gong Y, Lv G, 2019. Factors that alter the relative importance of abiotic and biotic drivers on the fertile island in a desert-oasis ecotone. Science of The Total Environment 697, doi.org/10.1016/j.scitotenv.2019.134096

Wang HJ, Riley WJ, and Collins WD. 2015. Statistical uncertainty of eddy covariance $\mathrm{CO}_{2}$ fluxes inferred using a residual bootstrap approach. Agricultural and Forest Meteorology 206:163-171. 10.1016/j.agrformet.2015.03.011

Wang J, Ding J, Li G, Liang J, Yu D, Aishan T, Zhang F, Yang J, Abulimiti A, and Liu J. 2019a. Dynamic detection of water surface area of Ebinur Lake using multi-source satellite data (Landsat and Sentinel-1A) and its responses to changing environment. Catena 177:189-201.

Wang J, Ding J, Yu D, Ma X, Zhang Z, Ge X, Teng D, Li X, Liang J, and Lizaga I. 2019b. Capability of Sentinel-2 MSI data for monitoring and mapping of soil salinity in dry and wet seasons in the Ebinur Lake region, Xinjiang, China. Geoderma 353:172-187.

Warton DI, Duursma RA, Falster DS, and Taskinen S. 2012. smatr 3- an R package for estimation and inference about allometric lines. Methods in Ecology and Evolution 3:257-259. 10.1111/j.2041210X.2011.00153.X

Webb EK, Pearman GI, and Leuning R. 2010. Correction of flux measurements for density effects due to heat and water vapour transfer. Quarterly Journal of the Royal Meteorological Society 106:85-100.

Williams M, Richardson AD, Reichstein M, Stoy PC, Peylin P, Verbeeck H, Carvalhais N, Jung M, Hollinger DY, and Kattge J. 2009. Improving land surface models with FLUXNET data. Biogeosciences 6:1341-1359.

Wohlfahrt G, Fenstermaker LF, and Arnone III JA. 2008. Large annual net ecosystem $\mathrm{CO}_{2}$ uptake of a Mojave Desert ecosystem. Global Change Biology 14:1475-1487.

Xie J, Li Y, Zhai C, Li C, and Lan Z. 2009. $\mathrm{CO}_{2}$ absorption by alkaline soils and its implication to the global carbon cycle. Environmental Geology 56:953-961. 


\section{Figure 1}

Aerial photograph of the tower site.

(a) Location map of the Ebinur Lake Basin, (b) Location map of the measurement tower, (c) aerial photo of the tower site in August (Photograph credit: Jinlong Wang), (d) photograph of the tower site in May (Photograph credit: Dexiong Teng), and (e) remote sensing image in June and the average footprint for the entire observation period (Kormann and Meixner, 2001). The measurement tower is marked with a red circle. The white lines represent isopleths of the average contributions.
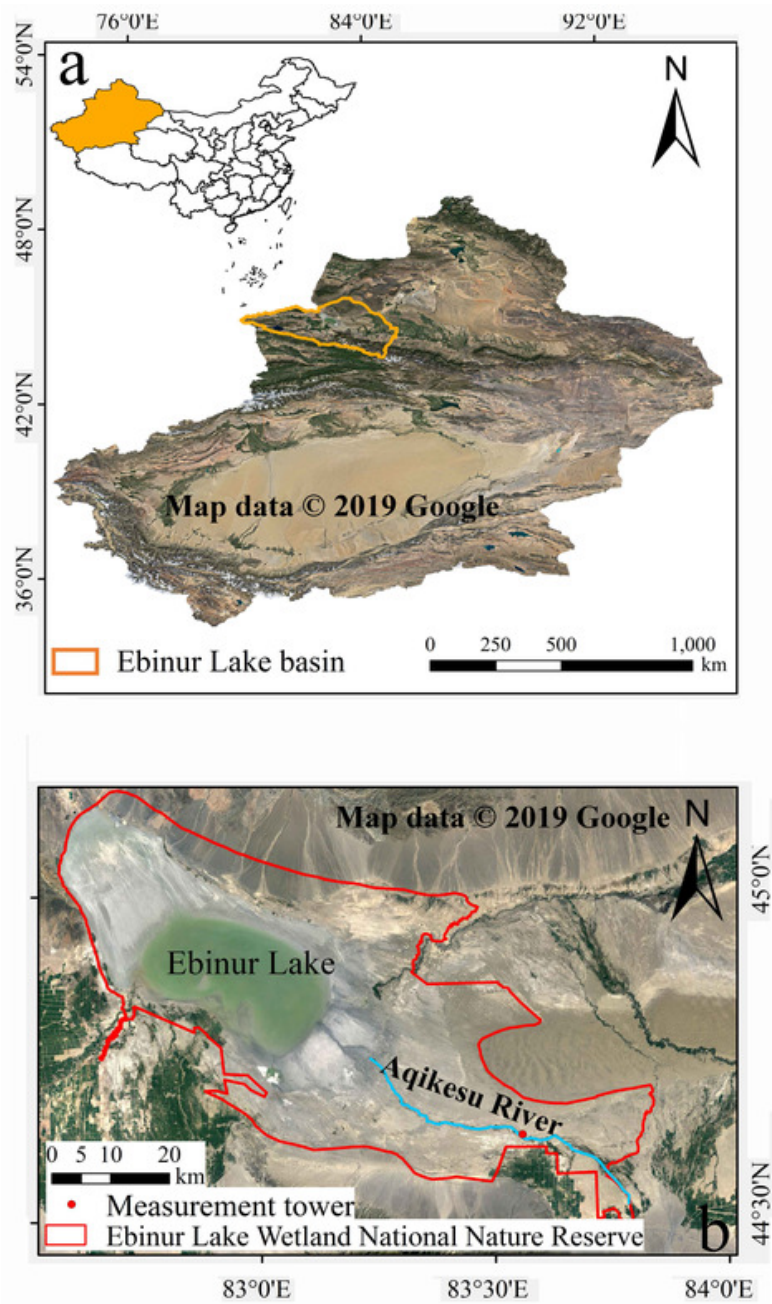
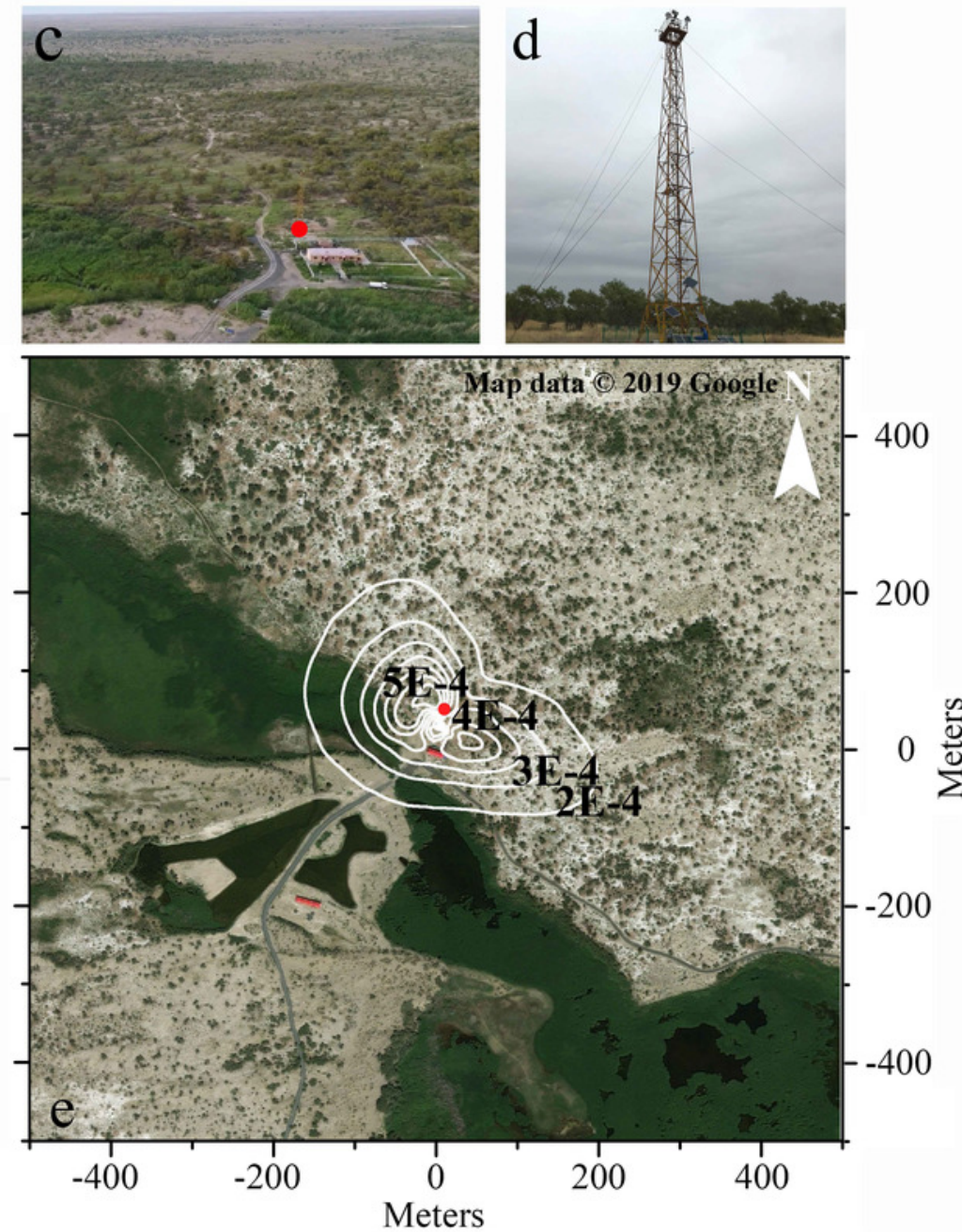
Figure 2

Meteorological observations during the year of measurement

Half-hour averaged values of (a) air temperature $\left(\mathrm{T}_{\text {air }}\right)$, (b) precipitation, (c) global radiation

$(\mathrm{Rg})$, (d) wind speed, and (e) relative humidity (RH) during the observation period 


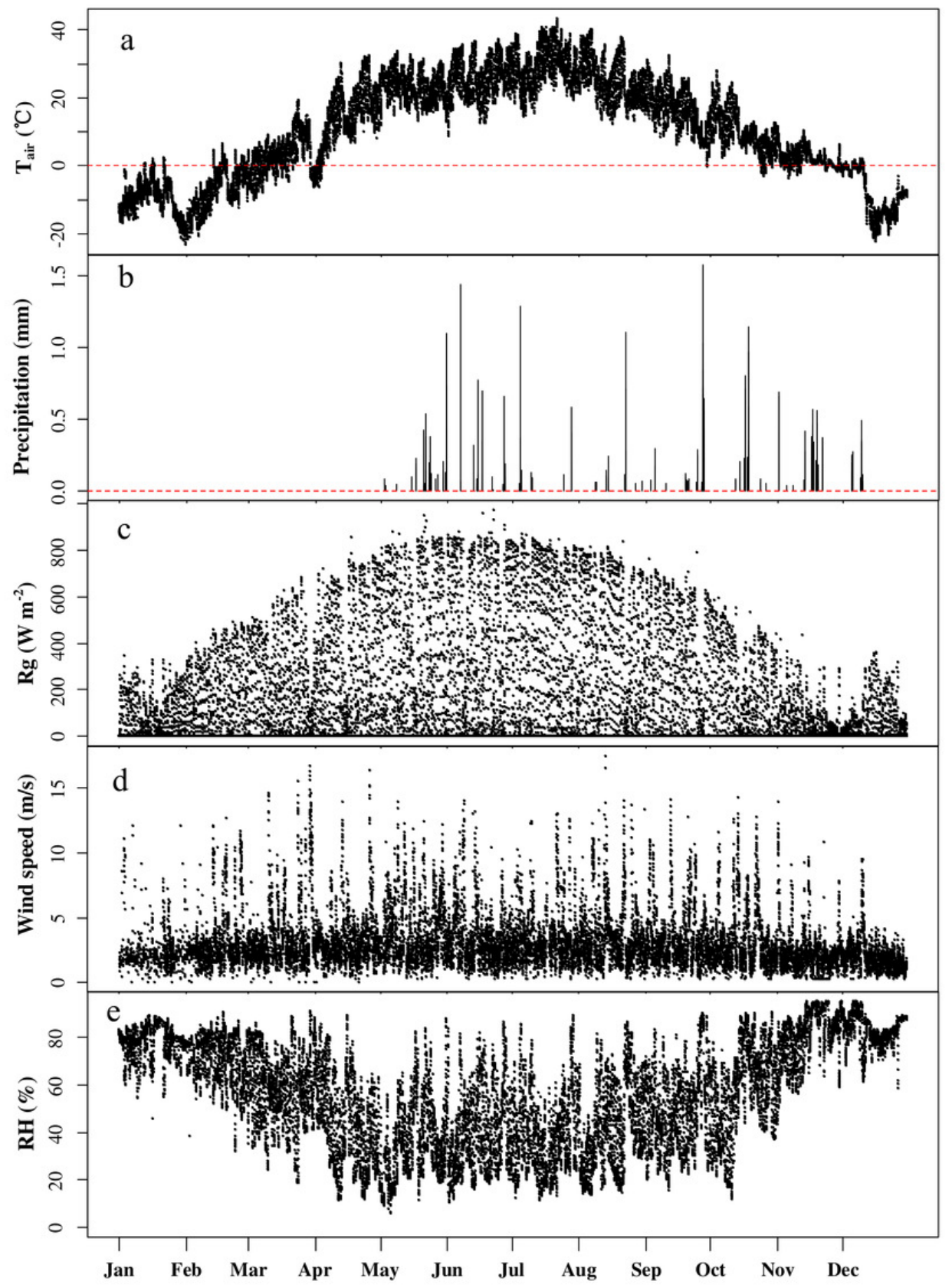




\section{Figure 3}

Mean diurnal courses of high-quality 30-min $\mathrm{F}_{\mathrm{c}}$ measurements averaged over 2-month periods after filtering: (a) Jan-Feb, (b) Mar-Apr, (c) May-Jun, (d) Jul-Aug, (e) Sep-Oct, and (f) Nov-Dec.

Within the boxes, the horizontal bars indicate medians, while the tops and bottoms of the boxes illustrate the $75^{\text {th }}$ and $25^{\text {th }}$ quartiles, respectively. Small circles represent outliers in the observations.
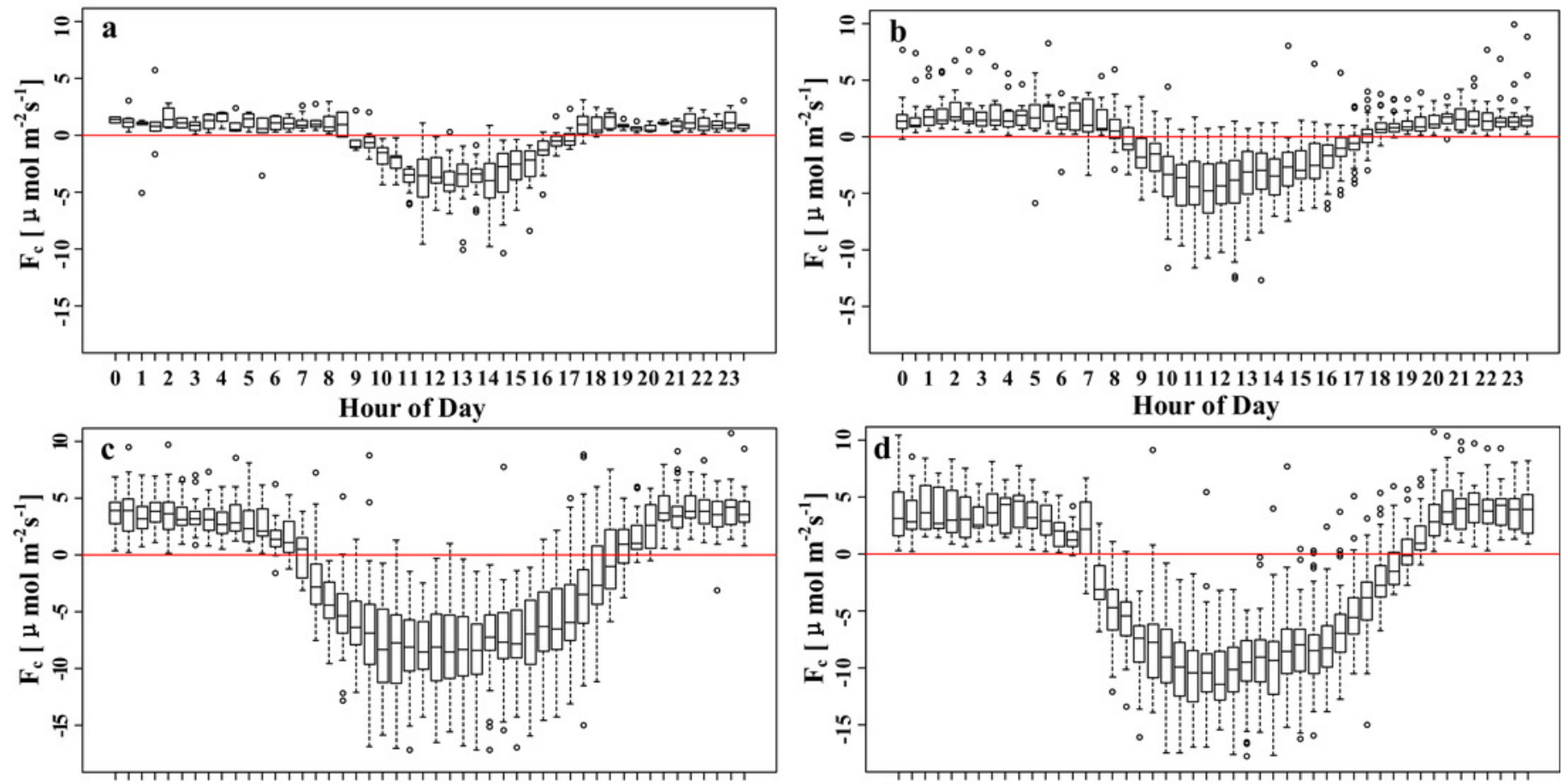

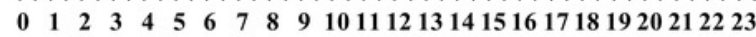
Hour of Day

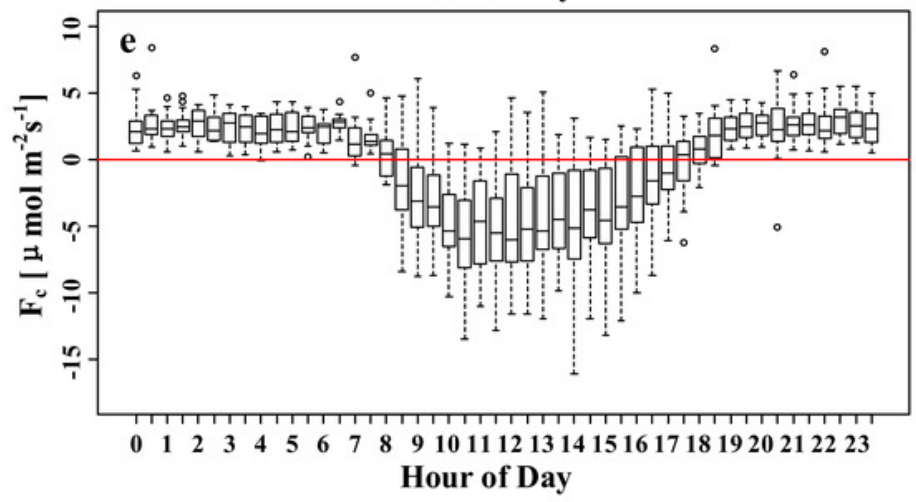

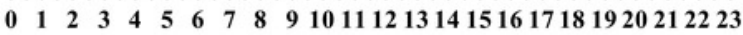

Hour of Day

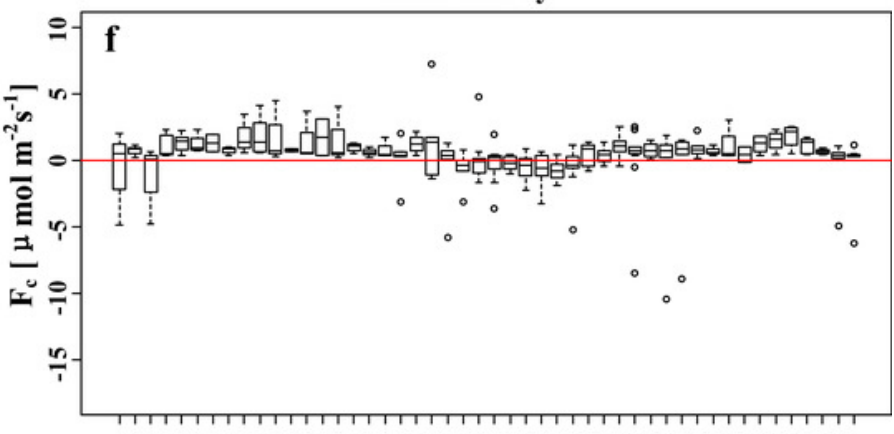

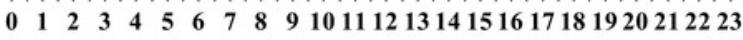
Hour of Day 
Figure 4

Histogram of the data gap distribution 


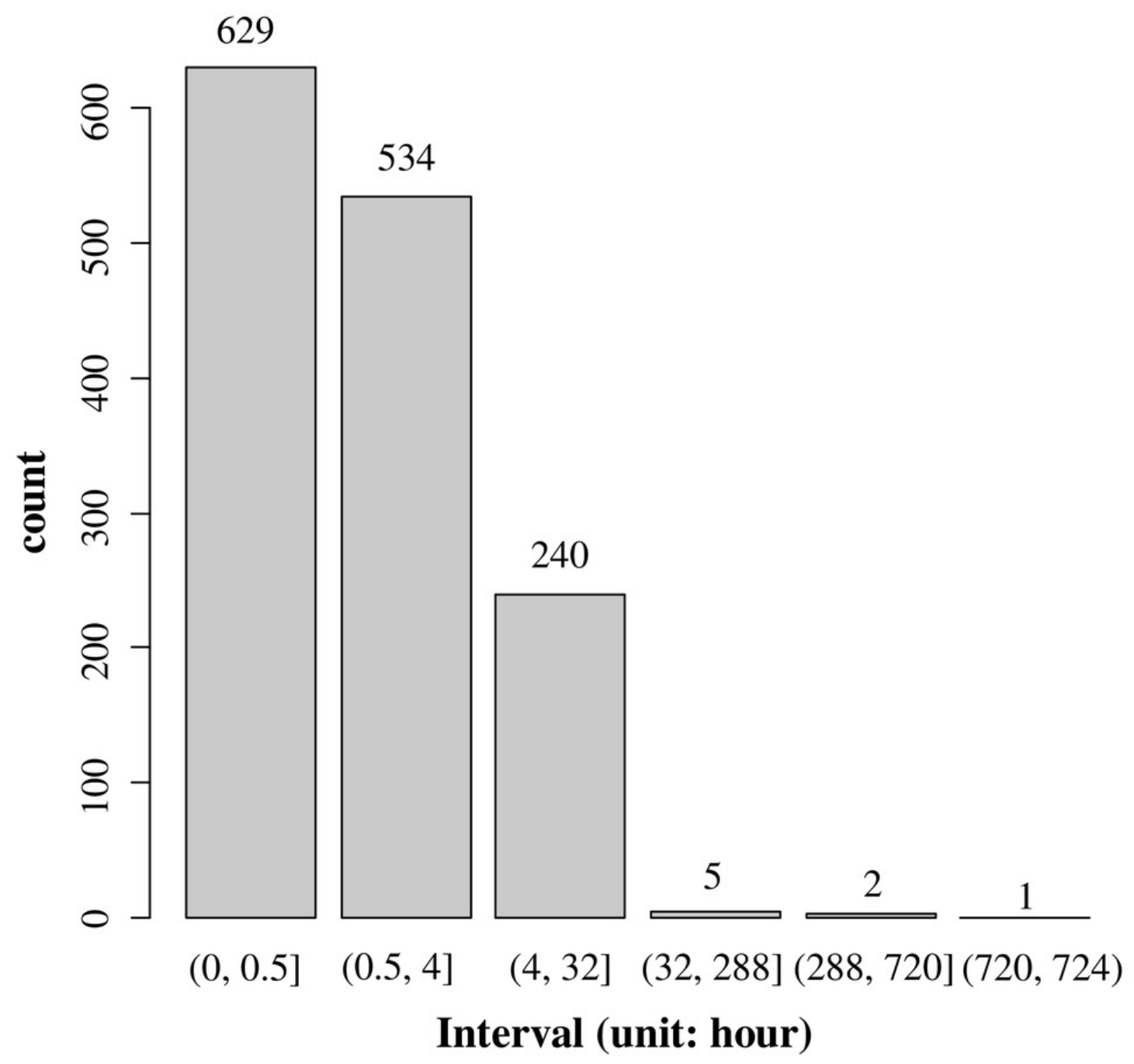


Figure 5

Time of $F_{c}$ and friction velocity $u^{*}$ observation times over the study year

Red, green, and blue represent $\mathrm{Qc}=0, \mathrm{Qc}=1$, and $\mathrm{Qc}=2$, respectively.

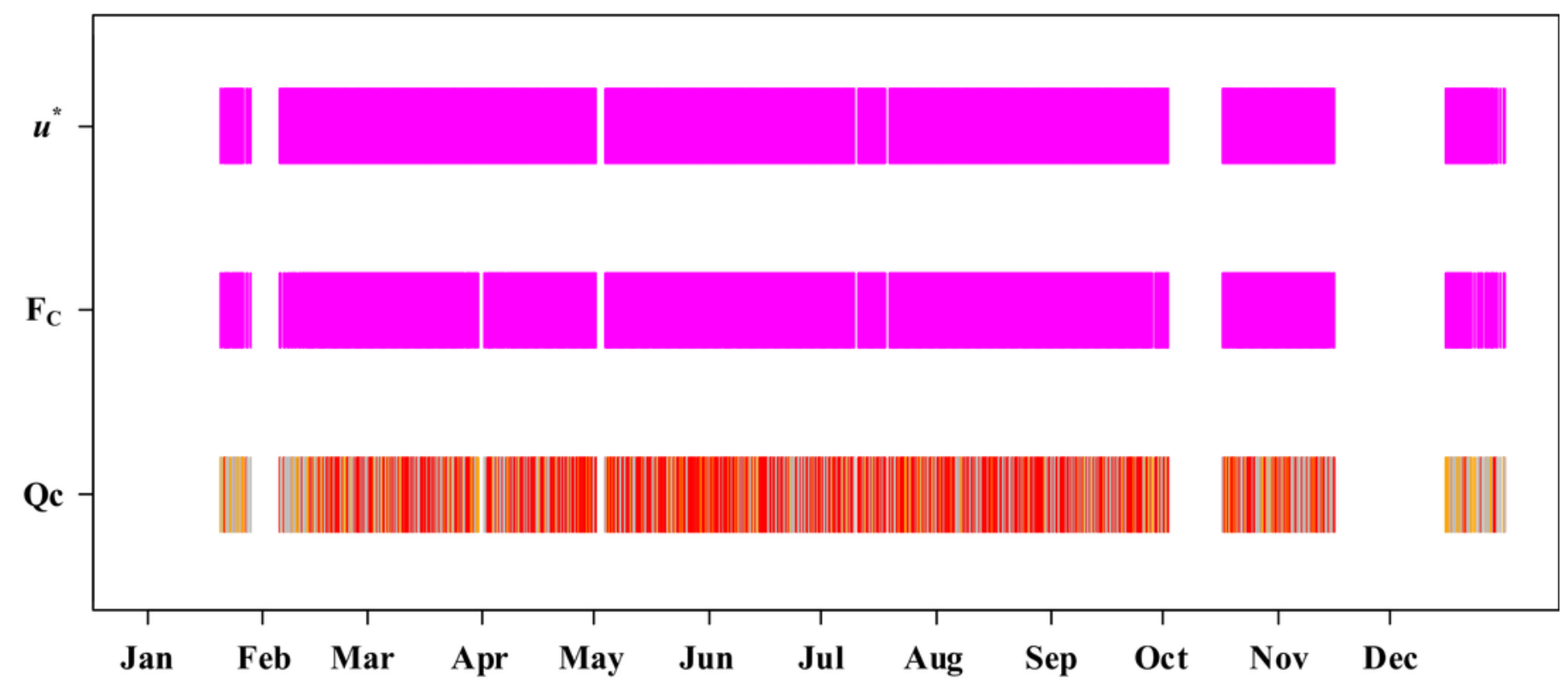


Figure 6

Values of nighttime friction velocity $u^{*}$ and wind speed

(a) Nighttime friction velocity $u^{*}$. (b) Nighttime wind speed. (c)The relationship between friction velocity and wind speed for all data was grouped by season. Green and gray represent the growing and non-growing seasons, respectively. Columns with different capital letters are significantly different $(p<0.05)$ according to Fisher's least significant difference test.
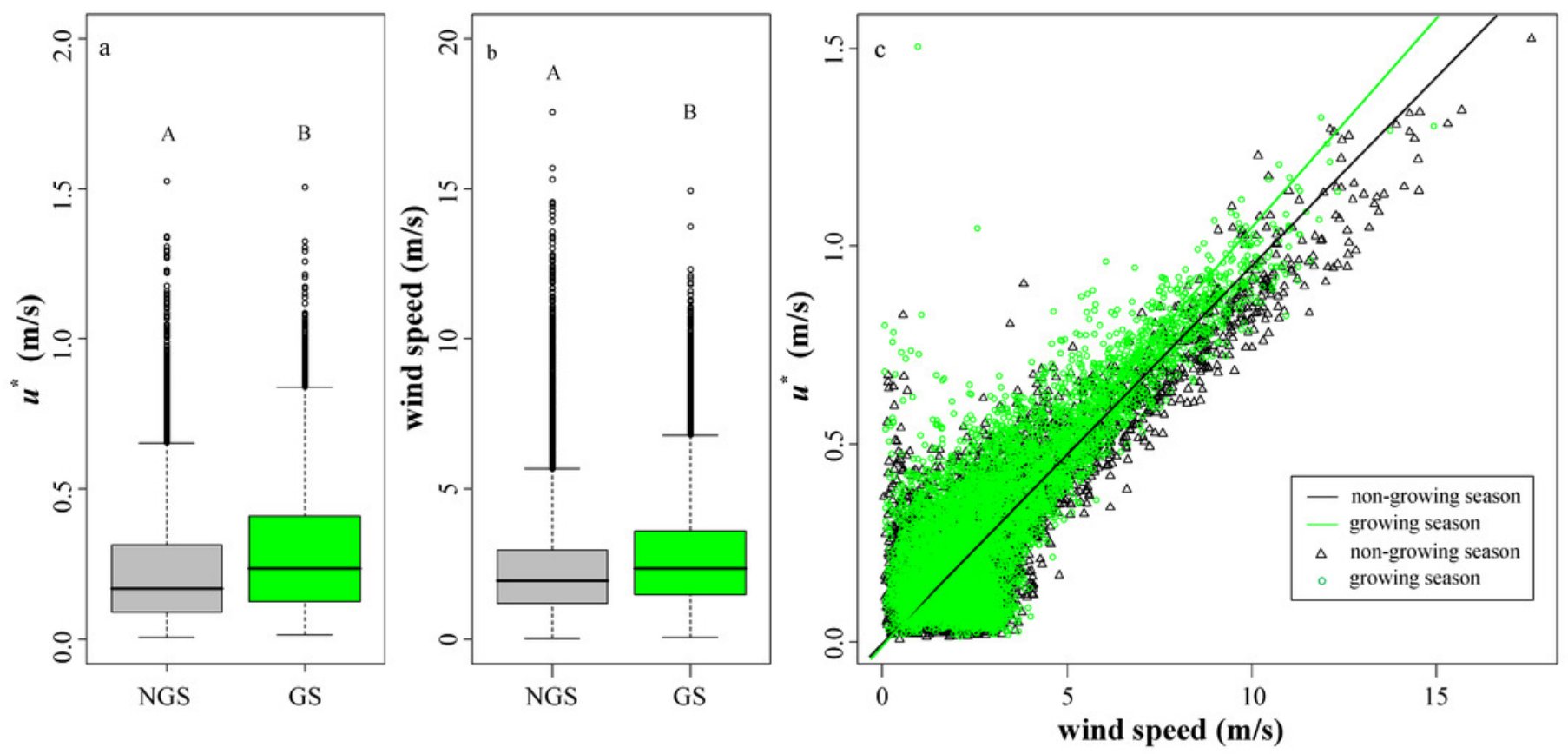


\section{Figure 7}

Training and test performances of the models for the dataset with 6,293 points

(a)ANN, (b)GP, (c)HLM, (d)RBF, (e) MDS. For comparison, the plotted lines consist of the training fit (solid black line), the test fit (green dotted line), and the 1:1 line (solid red). Units of RMSE and BE are $\mu \mathrm{mol} \mathrm{m}^{-2} \mathrm{~s}^{-1}$. 

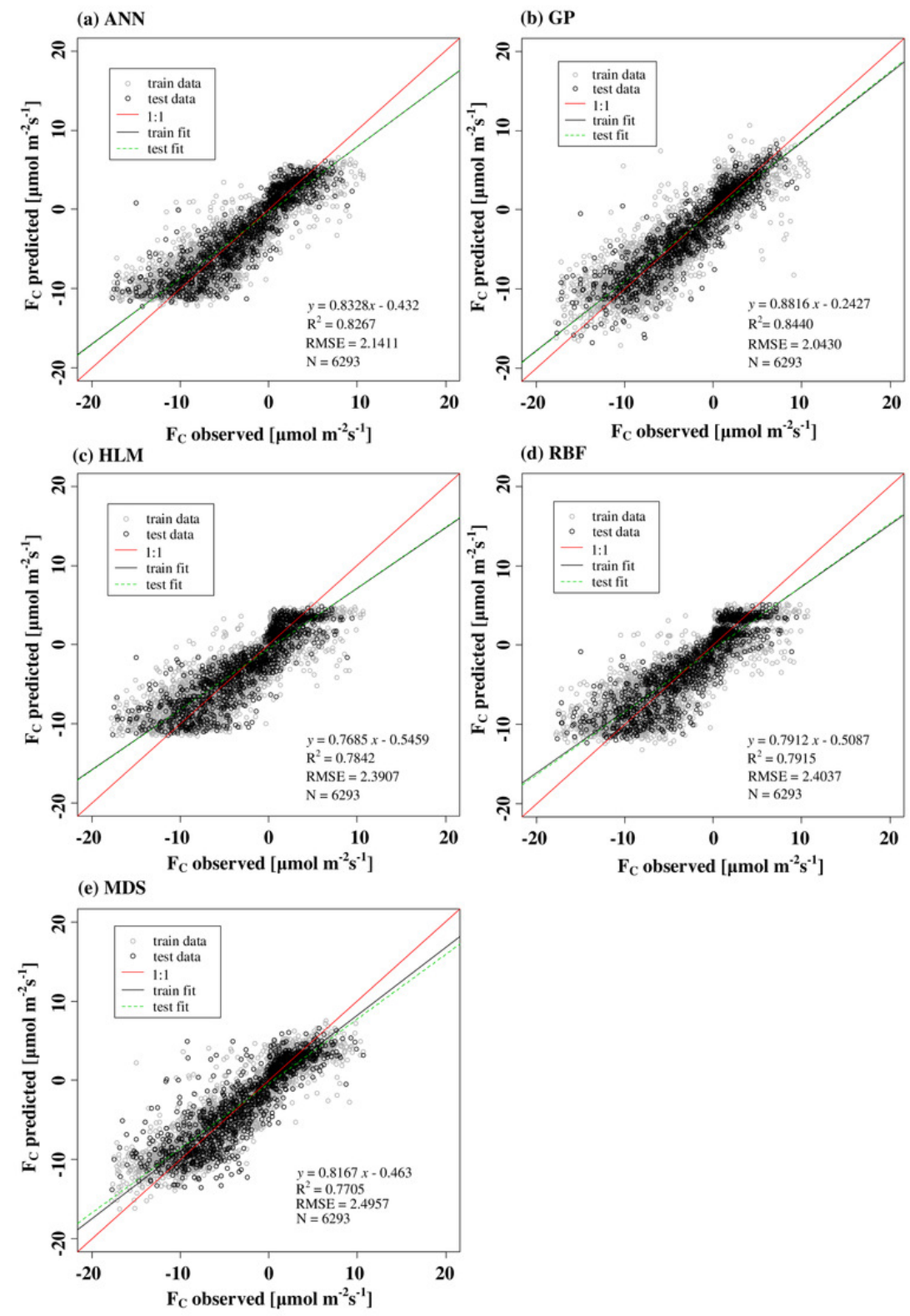
Figure 8

Fingerprints of the complete $F_{c}$ gap-filled by the (a) ANN, (b) GP, (c) HLM, (d) RBF, and (e) MDS methods
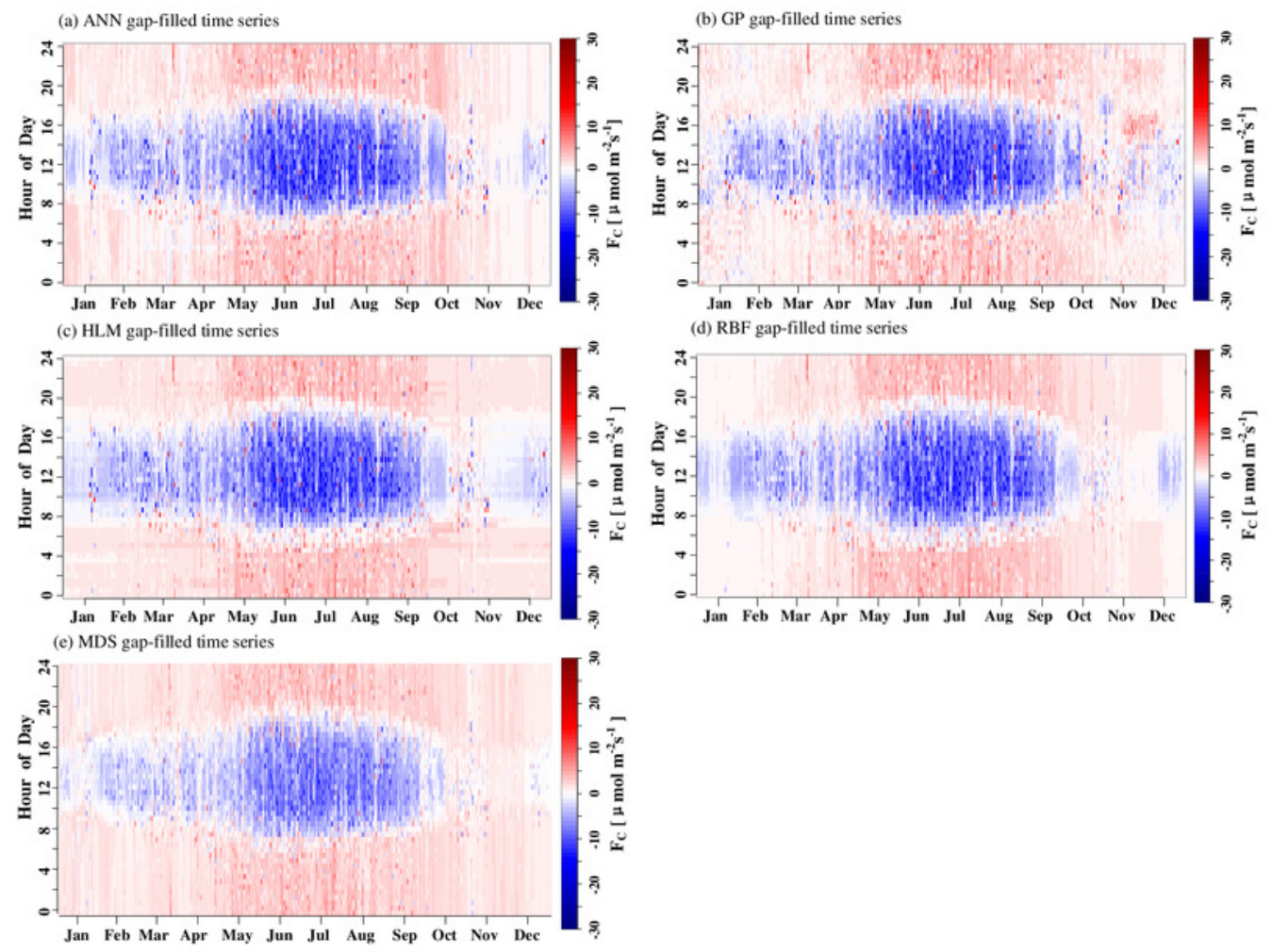
Figure 9

Empirical distributions of the residuals predicted by the five gap-filling methods and their corresponding Laplacian distributions

(a)ANN, (b)GP, (c)HLM, (d)RBF, (e) MDS. 

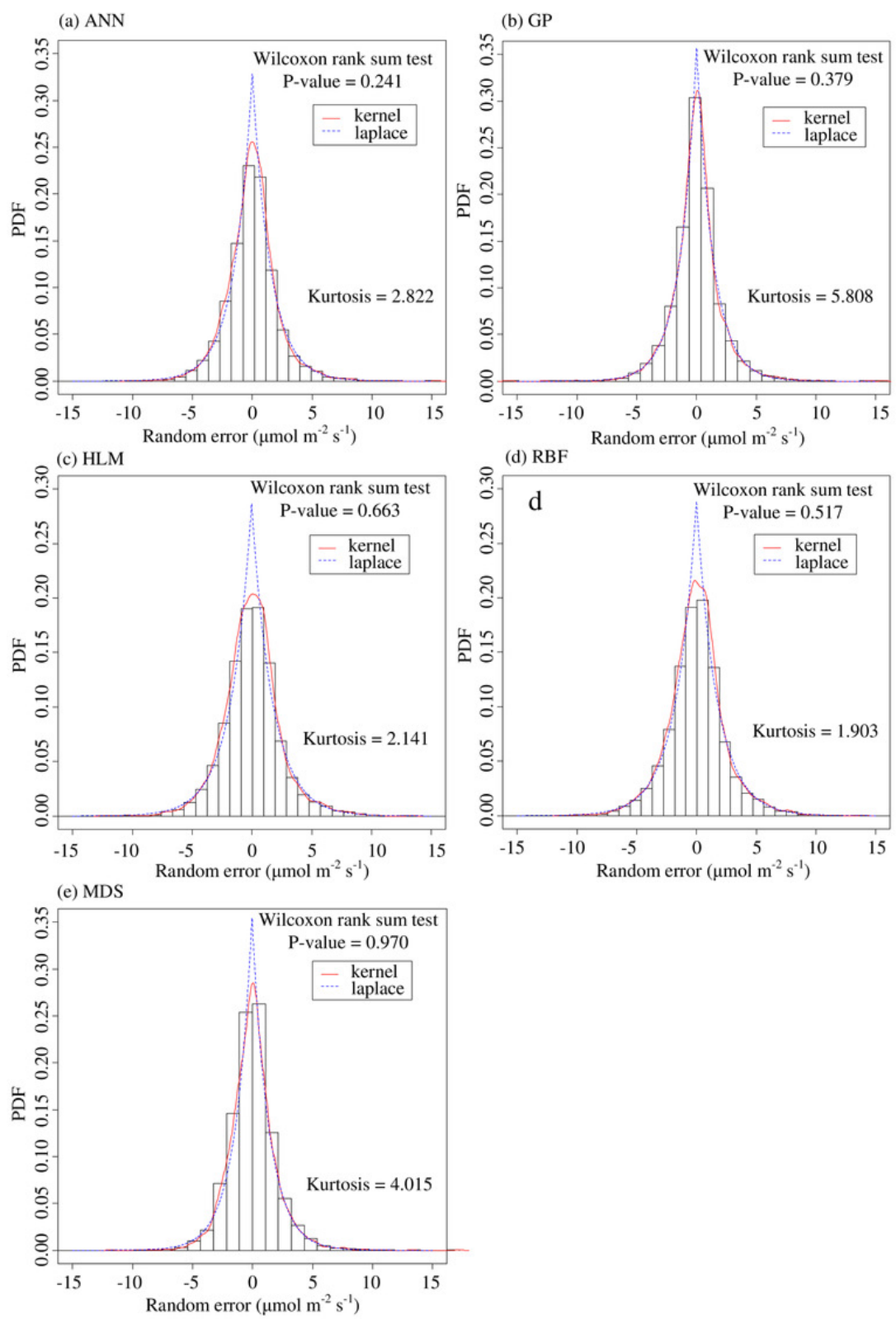
Figure 10

Cumulative carbon dioxide exchange obtained by the different methods

The data sources were composed of 3 parts, which were high-quality modeling data, data used to calculate annual sum of carbon dioxide exchange, and predictions from the different gap-filling methods.

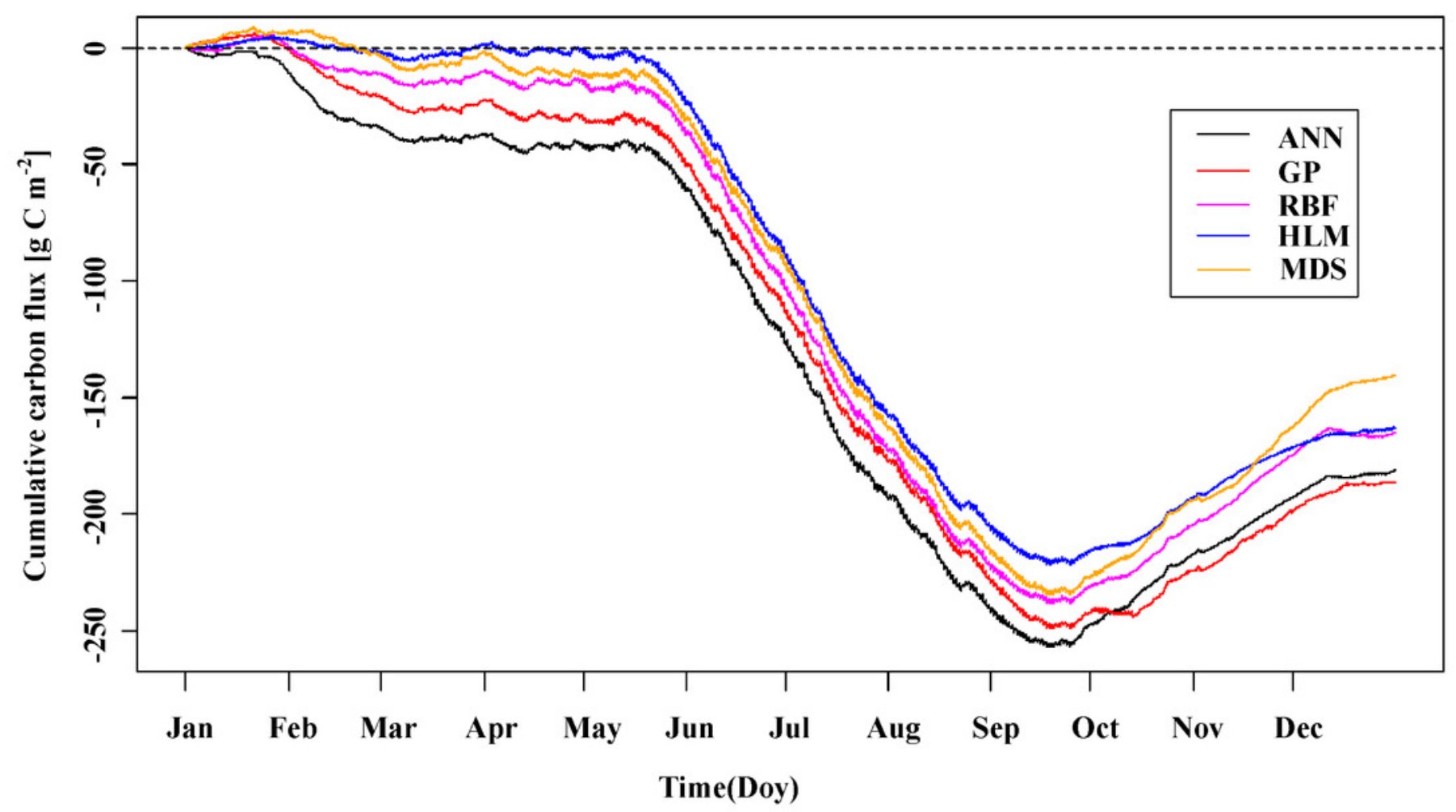




\section{Table $\mathbf{1}$ (on next page)}

Data source of the driving factors and their corresponding pre-processing 
Table 1. The data source of driving factors and their corresponding pre-processing

\begin{tabular}{llll}
\hline Variable & Name & Filled? & Pre-processing \\
\hline Daytime & hour $_{\mathrm{N}}$ & No & Cos conversion to daily time. \\
Daytime & hour $_{\mathrm{D}}$ & No & Sin conversion to daily time. \\
Daytime & Night & No & Calculated the sunrise and sunset times at the observation area location and marked the data from post-sunset to pre-sunrise as nighttime. \\
Daytime & Day & No & Calculated the sunrise and sunset time at the observation area location and marked the data from post-sunrise to pre-sunset as daytime. \\
Season & Season & No & Marked the data from May-September as the growing season. \\
Season & Season $_{\mathrm{N}}$ & No & Marked data from January-April and October-December as the non-growing season. \\
Vegetation index & NDVI & Yes & NDVI from $250 \mathrm{~m}$ resolution MODIS/Aqua remote sensing image for 16 days \\
Air temperature & $\mathrm{T}_{\text {air }}$ & Yes & Measured at a height of $15 \mathrm{~m}$ on the flux tower. \\
Soil temperature & $\mathrm{T}_{\text {soil }}$ & Yes & Measured at a soil depth of $5 \mathrm{~cm}$ under the flux tower. \\
Water vapor partial pressure & $\mathrm{E}$ & Yes & Measured at a height of $15 \mathrm{~m}$ on the flux tower. \\
Heating degree days & hdd & Yes & When $\mathrm{T}_{\text {air }}<18^{\circ} \mathrm{C}$, equal to $18^{\circ} \mathrm{C}$ - $\mathrm{T}_{\text {air }}$; otherwise, equal to 0. \\
Incident radiation & $\mathrm{Rd}$ & Yes & The sum of incident shortwave radiation and incident longwave radiation measured by NR01, Campbell Scientific, USA. \\
Scattered radiation & Ru & Yes & The sum of scattered shortwave radiation and scattered longwave radiation measured by NR01, Campbell Scientific, USA. \\
Water vapor pressure deficit & VPD & Yes & Measured at a height of $15 \mathrm{~m}$ on the flux tower. \\
Relative humidity & Rh & Yes & Measured at a height of $15 \mathrm{~m}$ on the flux tower. \\
\hline
\end{tabular}


Table 2 (on next page)

Quality control procedures for the 30-min flux data 
Table 2. Procedures of quality control of the half-hourly flux data

\begin{tabular}{|c|c|c|c|}
\hline \multirow{2}{*}{ Processing } & \multicolumn{2}{|c|}{ The number of outliers } & \multirow{2}{*}{ Description } \\
\hline & Growing season & Non-growing season & \\
\hline Quality control & 856 & 1021 & Cleaning carbon flux data based on QC flags and removing values while QC flags equal to 2 . \\
\hline Distributional cleaning & 679 & 464 & Cleaning carbon flux data based on flux distribution for each hour of the day. \\
\hline Filtering & 62 & 26 & Detecting and removing outliers in the continuous carbon flux data. \\
\hline$u^{*}$ screening & 216 & 192 & Cleaning carbon flux data based on friction vorticity threshold. \\
\hline
\end{tabular}


Table 3 (on next page)

Standardized major axis estimation and statistical inference 
1 Table 3. Standardized major axis estimation and statistical inference

\begin{tabular}{|c|c|c|c|c|c|c|}
\hline \multirow[t]{2}{*}{ Parameter } & \multicolumn{3}{|c|}{ Non-growing season } & \multicolumn{3}{|c|}{ Growing season } \\
\hline & Estimate & Lower $(2.5 \%)$ & Upper (97.5\%) & Estimate & Lower (2.5\%) & Upper (97.5\%) \\
\hline Elevation & $-4.039 e-3$ & $-8.112 \mathrm{e}-3$ & $3.399 \mathrm{e}-5$ & -0.011 & -0.015 & -0.006 \\
\hline Slope & 0.095 & 0.094 & 0.097 & 0.106 & 0.104 & 0.107 \\
\hline \multicolumn{7}{|c|}{$\mathrm{H}_{0}$ : variables uncorrelated. } \\
\hline P-value & \multicolumn{3}{|l|}{$<2.22 \mathrm{e}-16$} & \multicolumn{3}{|l|}{$<2.22 \mathrm{e}-16$} \\
\hline $\mathrm{R}^{2}$ & \multicolumn{3}{|l|}{0.730} & \multicolumn{3}{|l|}{0.706} \\
\hline \multicolumn{7}{|c|}{$\mathrm{H}_{0}$ : slopes are equal. } \\
\hline P-value & \multicolumn{6}{|l|}{$<2.22 \mathrm{e}-16$} \\
\hline \multicolumn{7}{|c|}{ Likelihood ratio statistic: 129.8 with 1 degrees of freedom } \\
\hline
\end{tabular}




\section{Table 4 (on next page)}

Kendall's tau $(\tau)$ coefficient between the 5 different methods of carbon flux prediction and the corresponding residuals 
Table 4. Kendall's tau $(\tau)$ coefficient between the four different methods of carbon flux prediction and corresponding residuals

\begin{tabular}{|c|c|c|c|c|c|c|}
\hline \multirow[t]{2}{*}{ Method } & \multicolumn{3}{|c|}{ Non-growing season } & \multicolumn{3}{|c|}{ Growing season } \\
\hline & $\mathrm{DAY}_{\mathrm{Rd}<=400}$ & $\mathrm{DAY}_{\mathrm{Rd}>400}$ & NIGHT & $\mathrm{DAY}_{\mathrm{Rd}<=400}$ & $D A Y_{R d>400}$ & NIGHT \\
\hline GP & $0.148^{* *}$ & $0.171^{* *}$ & $0.221 * *$ & $0.077 * *$ & $0.145^{* *}$ & $0.118^{* *}$ \\
\hline RBF & $0.048 *$ & 0.057 & $0.202 * *$ & $-0.290 * *$ & $0.082 * *$ & 0.005 \\
\hline ANN & $0.058 * *$ & 0.005 & $0.134 * *$ & 0.009 & -0.009 & $-0.059 * *$ \\
\hline HLM & $0.079 * *$ & 0.014 & $0.192 * *$ & $-0.175 * *$ & $0.033^{*}$ & $-0.060 * *$ \\
\hline MDS & $0.070 * * *$ & $0.071 * *$ & $0.074 * *$ & $0.182 * * *$ & $0.075 * * *$ & 0.012 \\
\hline
\end{tabular}

Notes: $* * *$ indicates p-value $<0.01 ; * *$ indicates $0.01<$ p-value $<0.05 ; *$ indicates $0.05<$ p-value $<0.1$. 


\section{Table 5 (on next page)}

Relationship between the magnitude of carbon flux and the standard deviation of random uncertainty 
Table 5. Relationship between the magnitude of carbon flux and the standard deviation of random uncertainty

\begin{tabular}{llll}
\hline Method & Intercept $(a)$ & Slope $(b)$ & $\mathrm{R}^{2}$ \\
\hline HLM & $1.5477 * * *$ & $0.0579 * * *$ & 0.3191 \\
ANN & $1.4001 * * *$ & $0.0608 * * *$ & 0.3047 \\
GP & $1.3290^{* * *}$ & $0.1082^{* * *}$ & 0.5906 \\
RBF & $1.5208^{* * *}$ & $0.0777 * * *$ & 0.4190 \\
MDS & $1.5550^{* * *}$ & $0.1092^{* * *}$ & 0.4513 \\
\hline
\end{tabular}

Notes: $* * *$ indicates $\mathrm{p}$-value $<0.01 ; \mathrm{R}^{2}$ indicates the coefficient of determination. 
Table 6 (on next page)

Annual sum and deviation of the carbon dioxide exchange estimated by the different methods 
Table 6. Annual sum and deviation of the carbon dioxide exchange estimated by the different methods

\begin{tabular}{|c|c|c|c|c|c|}
\hline \multirow{2}{*}{ Gap-filling method } & \multicolumn{2}{|c|}{ Annual sum of $\mathrm{CO}_{2}$ exchange } & \multicolumn{3}{|c|}{ Bias of Annual sum of $\mathrm{CO}_{2}$ exchange } \\
\hline & Mean & SD & Mean & Lower $(2.5 \%)$ & Upper $(97.5 \%)$ \\
\hline ANN & -159.91 & 18.35 & 0.84 & -9.55 & 10.73 \\
\hline GP & -178.25 & 8.01 & 11.22 & 1.37 & 21.71 \\
\hline $\mathrm{RBF}$ & -167.16 & 19.08 & 14.05 & 2.63 & 25.89 \\
\hline HLM & -156.95 & 3.15 & -2.64 & -14.65 & 9.55 \\
\hline MDS & -155.21 & 5.16 & -13.69 & -23.70 & -4.20 \\
\hline
\end{tabular}




\section{Table 7 (on next page)}

Seasonal sum of carbon dioxide exchange estimated by the different methods 
1 Table 7. Seasonal sum of carbon dioxide exchange estimated by the different methods

\begin{tabular}{|c|c|c|c|c|c|c|}
\hline \multirow[t]{2}{*}{ Method } & \multicolumn{2}{|c|}{ Non-growing season } & \multirow[b]{2}{*}{ Upper $(97.5 \%)$} & \multicolumn{2}{|c|}{ Growing season } & \multirow[b]{2}{*}{ Upper $(97.5 \%)$} \\
\hline & Mean & Lower $(2.5 \%)$ & & Mean & Lower $(2.5 \%)$ & \\
\hline GP & 39.788 & 33.877 & 46.264 & -220.245 & -227.814 & -212.417 \\
\hline $\mathrm{RBF}$ & 68.292 & 62.380 & 74.767 & -232.510 & -240.080 & -224.682 \\
\hline ANN & 56.000 & 50.088 & 62.476 & -216.624 & -224.194 & -208.796 \\
\hline HLM & 61.033 & 55.121 & 67.508 & -227.859 & -235.428 & -220.031 \\
\hline MDS & 74.954 & 69.042 & 81.429 & -229.959 & -237.529 & -222.131 \\
\hline
\end{tabular}

2 